\title{
ATERIALS I PROCEDIMENTS ARTÍSTICS UTILITZATS PELS PINTORS I ARTESANS DE VALĖNCIA EN LA CONFECCIÓ DELS ENTREMESOS DE LES ENTRADES DEL REI MARTÍ I EL REI FERRAN $(1402,1414)$
}

\author{
MIQUEL A. HERRERO-CORTELL \\ CAEM, Universitat de Lleida \\ miquelangel.herrero@hahs.udl.cat \\ ISIDRO PUIG SANCHIS \\ CAEM, Universitat de Lleida \\ isidro.puig@udl.cat
}

\begin{abstract}
Resumen: El presente artículo propone una revisión de las materias primas de índole artística consignadas en la documentación de las compras y preparativos realizados con motivo de las entradas reales en Valencia de Martín I y Fernando de Antequera. A través del análisis de materiales abordado desde el estudio teórico-práctico de la praxis artística, se deducen los diversos procedimientos de creación que los artesanos llevaron a cabo en la ejecución de carrozas o 'Rocas', y escenografías, para los entremeses.
\end{abstract}

Palabras clave: Entradas reales / rocas / arte efímero / pintura / escultura.

Abstract: The aim of this article is to make a review of the artistic materials contained in the documentation of purchases and preparations made on the occasion of the royal entrances in Valencia of the kings Martin I, and Fernando de Antequera. Through an exhaustive analysis of materials, approached from the theoretical and practical study of artistic practice, the various processes of creation carried out by local artisans in he execution of floats or 'Rocks ' and sets, are deducted.

Key words: Royal entries / floats / ephemeral art / painting / sculpture.

\section{Introducció, plantejament i metodologia'}

Les publicacions als darrers anys dels reculls documentals corresponents a les compres i despeses fetes per la ciutat de València amb motiu de les entrades reials del rei Martí I (1402)2 i el rei Ferran $\mathrm{d}^{\prime}$ Antequera (1414) ${ }^{3}$ han suposat una valuosíssima contribució per a l'estudi històric, social, i artístic i de la festa cívica valenciana. Les dades aportades pels esmentats reculls documentals poden interpretar-se en diverses claus i, tot i l'abundància d'estudis que ha comportat la publicació de la mencionada documentació, en part, encara queden alguns aspectes en els que caldrà aprofundir en successius estudis, atès que es tracta de veritables 'jaciments' que poden explotar-se de diversos enfocaments.

Els orígens de la festa, les seues analogies dins dels territoris de la Corona, així com la seua repercussió i incidència han estat ben estudiats, tot i emfatitzant en aspectes històrics, socials polítics, protocol-laris, estratègics, al-legòrics, culturals, etc. També, les analogies amb l'organització de la festa del Corpus Christi a València s'han subratllat com molt rellevants, des del seu recorregut a la manera en la que van organitzar-se com a festes coordinades i orquestrades directament per la ciu\footnotetext{
ricos de la Corona de Aragón (S. XV-XVI)".

2 ALIAGA, Joan; TOLOSA, Lluïsa; COMPANY, Ximo, 2007.

3 CÁRCEL ORTÍ, María Milagros; GARCÍA MARSILLA, Juan Vicente, 2013.
}

* Fecha de recepción: 15 de octubre de 2016 / Fecha de aceptación: 12 de diciembre de 2016.

1 Aquest article s'inscriu dins del Grup de Recerca consolidat: 'Art i Cultura d'Època Moderna' (ACEM) reconegut per la Generalitat de Catalunya, i s'ha pogut realitzar també gràcies a l'aportació del Ministeri d'Educació Cultura i Esport (FPU14/01768) per al desenvolupament de la tesis doctoral "Procedimientos técnicos, soportes y materiales utilizados en los obradores pictó- 
tat. ${ }^{4}$ La participació dels diversos gremis en la confecció i desenvolupament de les tasques de preparació de les entrades permet aproximacions tant al món artesanal -des de la seua jerarquització, al seu estatus social o al nivell d'implicació dels diversos oficis- ${ }^{5}$ com a qüestions de simbolisme corporatiu i de protocol al sí d'una gran urbs medieval com va ser València, i tot plegat ens permet entreveure com va donar-se l'evolució mateixa de les arts escèniques en la festa cívica d'aquella ciutat. $^{6}$ L'organització concreta de les respectives desfilades és un punt del que encara es poden extraure algunes conclusions, i en aquest sentit cal destacar la importància dels estudis introductoris desenvolupats per a la publicació de la documentació al-lusiva a les dues entrades. ${ }^{7}$ No obstant, considerem que encara resta realitzar un estudi exhaustiu dels entremesos i les diverses carrosses, roques i escenografies de l'entrada del rei Martí ${ }^{8}$ (tot i incloent una descripció concreta dels personatges, vestuaris i aparença morfològica que degueren tindre cadascuna d'aquelles manifestacions), ${ }^{9}$ que ens permetin apropar-nos a la realitat visual i formal d'aquell espectacle.

D’altra banda, malgrat l'enorme aportació per a I'anàlisi econòmic i mercantil, a través del valor dels materials que suposen les llistes detallades de les compres i pagaments, i més enllà de l'estudi exempt de les matèries que ens permeten conèixer el mercat de productes a l'abast del que disposaven els pintors, ${ }^{10}$ un altre aspecte que veritablement pot resultar útil és fer-ne una lectura conjunta per tractar d'esbrinar quins procediments artístics van fer servir els artesans de València. Així podem avaluar el seu grau de coneixença tècnica, tot i establint les corresponents analogies amb altres procediments artístics que tenim més àmpliament documentats, per apropar-nos, en última instància a una altra vessant de l'estudi: la de la realitat material d'aquelles mostres d'art efímer. El principal problema al qual ens enfrontem és que, mentre que podem estudiar la composició i els procediments utilitzats a retaules i peces mobles amb els moderns sistemes químics i analítics, no ens queda gairebé cap mostra d'aquestes construccions passatgeres que ens ajudi a rastrejar com van fer-se. ${ }^{11}$ Per aquest motiu, el seu estudi procedimental i tècnic està limitat per la mancança d'exemples conservats d'aquella època, el que ens obliga a fer una lectura tècnica antropològica, fonamentada en la recerca dels materials i procediments pictòrics de l'època, i no ens queda més remei que comparar

${ }^{4}$ En aquest sentit destaquen referències com BOIX, Vicente, 1858; CARRERES ZACARES, Salvador, 1925; NARBONA, Rafael, 1999, pp. 371-382; ALEJOS MORÁN, Asunción, 2003, pp. 667-712, per citar-ne algunes.

${ }^{5}$ Vegeu IZQUIERDO, Teresa, 2012, pp. 108-114.

${ }^{6}$ Són molt abundants els estudis sobre la festa cívica a València, entre els que destaquem: BOIX, Vicente, 1858; CARRERES ZACARÉS, Salvador, 1925; NARBONA, Rafael, 1993, pp. 463-472; FERRER VALLS, Teresa, 1994, pp. 145-169; NARBONA, Rafael, 2003, i són també extensibles a altres ciutats de la Corona d'Aragó, com: LADERO, Miguel Ángel, 1994, pp. 11-52; MASSIP, Francesc, 1996, pp. 371-386; KOVÁCS, Lenke, 2003, pp. 71-82; MASSIP, Francesc, 2003, pp. 131-136; RAUFAST, Miguel, 2006, pp. 651-686; RAUFAST, Miguel, 2007, pp. 91-130; CHAMORRO, Alfredo, 2009, pp. 427- 437; tot i que, donat a l'enfocament històric-social que presenten, cap d'ells no aprofundeix en absolut en aspectes materials. Sí trobem en canvi alguns estudis sobre el paper dels pintors dins la festa a València i altres territoris de la Corona, a títols com ara: MIRÓ BALDRICH, 1985 ; MOLINA, Joan, 1992, pp. 173-180; MIQUEL, Matilde, 2011, pp. 201-217; VIDAL FRANQUET, Jacobo, 2011, pp. 12-22; o MONTERO TORTAJADA, Encarna, 2014, pp. 351-369.

7 ALIAGA, Joan; TOLOSA, Lluïsa; COMPANY, Ximo (ed.), 2007, pp. 13-25, nota 2; i CÁRCEL ORTÍ, María Milagros; GARCíA MARSILLA, Juan Vicente, 2013, pp. 7-25, nota 3.

${ }^{8}$ Per al cas de l'entrada del rei Ferran resulta molt interessant l'article de MASSIP, Francesc, 2013-2014, pp. 55-65.

${ }^{9}$ A pesar de la coneguda dificultat per poder interpretar objectivament com van ser aquells entremesos (vegeu CÁRCEL ORTí, María Milagros; GARCÍA MARSILLA, Juan Vicente, 2013, p. 12), sí és possible, almenys, poder-ne fer una aproximació amb les dades oferides pels dos reculls documentals.

10 Un aspecte que ha estat molt ben abordat en el capítol 'El preu de la bellesa', en GARCÍA MARSILLA, Juan Vicente, 2011, pp. 71-91. L'autor repara en els diversos materials que conformen la realitat formal de les obres d'art de la baixa Edat Mitjana, tot i prestant una especial atenció als preus de les substàncies, i a les seues fluctuacions.

11 Tot i que en tenim d'alguns antics, a partir del segle XVI (1511-1512), que ens permeten apropar-nos a la manera en la que tradicionalment s'ha donat solució a la construcció d'aquelles carrosses, el seu estudi ha de fer-se amb certes reserves atès que es tracta de carrosses elaborades per a la processó del Corpus Christi, que ja no tenien un caràcter tan netament efímer, i per a les quals van utilitzar-se materials més duradors, principalment la fusta, prescindint en major mesura d'altres com el cartó o el paper. Són molt interessants les aportacions de: SIMÓN, José Manuel; VIVANCOS, María Victoria; GRAFIÁ, José Vicente, 2010, pp. 69-72, i TALAMANTES, María del Carmen, 2012. La escultura del Sant Miquel de l'Ajuntament de València, o la imatge original de la Verge dels Desamparats de la Reial Basílica homònima, constitueixen dos exemples importants d'escultures realitzades amb materials lleugers amb un procés molt similar al que es va seguir en la confecció dels modelats d'aquelles carrosses. Pel cas del San Miquel vegeu SARRIÓ, Ma Francisca; JUANES, David; FERAZZA, Livio, 2017, pp. 9-24, i el cas de la imatge original la Verge dels Desamparats en la mateixa publicació a càrrec de GARCíA, Greta; ROMÁN, Rosa María, 2017, pp. 146160. 
aquests procediments amb els habituals dins la praxis pictòrica pintura de la Corona d'Aragó, tot i que també s'han tingut en compte altres mostres de carrosses triomfals, roques i elements semblants utilitzats a la processó del Corpus a València, tot i ser vora un segle posteriors.

Com a premissa inicial, cal tenir en compte que, juntament amb els fusters, el principals artesans involucrats en la construcció dels entremesos van ser els pintors, amb els qui sovint compartien gremi. Es per això que aquest article es centra de forma especial en els processos artístics (pictòrics i escultòrics), desenvolupats majorment pels pintors, en una concepció probablement més colorista que no pas escultòrica i volumètrica de les roques i entremesos, tal i com suggereixen les pròpies adquisicions de matèries i materials. Altres qüestions, com sistemes d'enginyeria mecànica, ornaments i altres complements queden fora del marges d'aquest estudi i sols s'esmenten de forma tangencial.

\section{Materials i matèries primeres}

L'estudi dels materials i matèries primeres, per la seua elecció, permet, com s'ha dit, una aproximació a la tècnica. S'han organitzat els diversos tipus de substàncies i compostos segons la seua funció dins els diferents procediments que apareixen descrits a l'epígraf següent. S'inclouen, a més de les referències de cada material als respectius documents, altres aportacions de tractats i receptaris artístics, així com observacions al-lusives a la tècnica extretes d'investigacions de caire procedimental, tant a nivell específic com genèric.

\subsection{Pinzells}

La confecció dels pinzells és un procés molt lent que requereix certa perícia, en tant els pinzells s'esdevenen, en part, responsables directes de l'acabat d'una obra. Pel que sembla a la documentació existent aquests instruments no eren objectes de comerç, ${ }^{12}$ sinó que constituïen una eina que es fabri- cava el propi pintor segons les seues necessitats, i que presumiblement duraria relativament poc en òptimes condicions, raó que feia que els aprenents haguessin de controlar la seua correcta fabricació. Un pinzell de qualitat permet un treball molt més còmode i precís, i a tenor dels resultats artístics que conservem, es pot determinar que, sens dubte, els pinzells $d$ 'aquella època eren tan sofisticats com els d'ara i, de fet, les dos grans varietats de pinzells que coneguem per la documentació -els de cerres i els de pèl-, es segueixen fabricant encara avui, i constitueixen eines bàsiques per a qualsevol pintor. ${ }^{13}$ Són habituals les compres de matèries primeres ${ }^{14}$ per fabricar-los, com:

Plomes d'oca, i de voltor: de les plomes gruixudes, sòls s'aprofitava la cànula o 'canó'. Desprès de desbarbar-les es tallava una petita peça cilíndrica, d'uns 6 a $8 \mathrm{~cm}$, que serviria per inserir el mànec i el manoll o feix de pels.

Coes (cues) de 'vanys': Els pèls, per a fer pinzells fins, que s'utilitzaven especialment per pintar detalls (però que eren els comuns en la pintura de retaules) s'extreien de les cues d'una mena d'esquirols, que s'anomenaven 'vanys' (tot i que també trobem la paraula esquirol a la documentació). Aquestes cues posseïen uns pels fins i suaus, amb la suficient consistència per recollir la pintura i escampar-la amb precisió, permetent, al mateix temps, una alta capacitat de retenció de la pasta pictòrica al seu sí, el que afavoreix trets llargs, i un ús precís de la punta que faciliti els trets fins, amb total control de la descàrrega.

'Cerdes' (Cerres): Per a pinzells que havien d'abastir una major superfície específica, i que havien de suportar un major castic s'utilitzaven les cerres dels porcs blancs i negres, que no permetien un treball massa precís però que resultaven molt eficients per a pintar i envernissar cadafals, grans estructures, taulons, etc. A banda, és molt possible que s'utilitzessin també d'altre tipus de fibres com pèls de cabra, conill o fins i tot gos, en funció de la duresa requerida i l'ús al que estaven destinats. ${ }^{15}$

\footnotetext{
12 DOERNER, 1998, p. 282, ja ens indica que no va ser fins el final del segle XVII i començament del XVIII quan passen a ser un objecte de comerç.

${ }^{13}$ Cennini recull els dos tipus de pinzells i la manera de fabricar-los, tot i remarcant la importància de saber-los preparar. CENNINI, Cennino, 1988, pp. 109-112. Cal esmentar que els receptaris tècnics medievals no solen incorporar instruccions sobre la preparació dels pinzells, que sí trobem amb més freqüència en canvi en altres textos a partir del segle XVI.

${ }^{14}$ Les compres i adquisicions d'aquestes matèries primeres per a la confecció de pinzells es documenten més vegades al llarg del segle a València. Per posar un exemple, aproximadament uns setanta anys més tard, amb motiu de l'aprovisionament de materials realitzat per als diversos projectes de pintures murals de la Capella Major de la Catedral de València s'hi documenten de nou compres de totes aquestes matèries. Vegeu: COMPANY, Ximo, 2006, docs. 42 y 44, p. 398, docs. 125 y 126, p. 406. Aquestes mateixes matèries apareixen també als inventaris de bens dels pintors, com succeeix amb el cas de les plomes esmentades a l'inventari de Jaume del Port. SANCHIS SIVERA, José, 1914 pp. 90-91.

15 DOERNER, Max, 1998, p. 283.
} 
La cendra servia com a desgreixador dels pèls d'animal (encara avui, al Japó, l'únic Iloc on ha perviscut la tradició artesanal de la fabricació de pinzells) s'utilitza cendra de palla d'arròs. El mànec es feia amb un palet de fusta, polit i arrodonit i amb certa punta a l'extrem, que en ocasions era utilitzada per esgrafiar sobre la pintura fresca i per retirar aquesta de la làmina d'or. El mànec s'hi unia amb cola i fil de torçal. Les brotxes, de naturalesa més modesta, solien muntar-se amb un mànec de canya.

\subsection{Coles}

Les coles, anomenades en la documentació 'aiguacuit' o 'aiguacuita' constituïen un dels materials més importants en la confecció dels entremesos, i n'estaven presents en molts dels processos artístics, des de la unió de fustes, taulons, bigues i llistons, fins la preparació dels estucs, la fabricació del pinzells i d'altres estris, els engruts, les pintures, les 'sises' i els vernissos. Es tracta de compostos orgànics i proteics a base de collagen, que s'extreia del pergamins, pells d'animal, ossos, tendons i cartílags. En funció de la procedència de cada cola, la seua duresa era major o menor, tot i que aquesta també podia controlar-se, en certa manera, segons la concentració o dissolució. L'aiguacuita o aiguacuit va ser la cola més emprada, sens dubte, si atenem a les fonts. Es tractava d'un material elaborat amb pells (també amb pergamins, tot i que amb un poder adhesiu menor) que apareix ben definida i formulada als diversos receptaris de l'època. ${ }^{16}$ Aquest adhesiu podia comprar-se deshidratat, o bé ja hidratat. El pintor Domingo del Port sembla ser qui abasteix la resta de pintors amb pergamins per tal de fabricar l'adhesiu.

\subsection{Pigments}

Són molt habituals els estudis i és molt extensa la literatura disponible sobre els pigments i colorants en l'Edat Mitjana i l'inici del renaixement, ${ }^{17} \mathrm{i}$ per això ens limitarem a exposar aquells que apareixen citats en la documentació que ens afecta, sense entrar, per la obvia limitació de l'espai, en la seua producció, fabricació, preu, etc., aspectes que sens dubte mereixen estudis específics. ${ }^{18}$

La immensa majoria d'aquests materials eren subministrats per especiers i apotecaris, doncs es tractava de matèries de cost elevat, tot i que hi havia notables diferències entre els seus costos. ${ }^{19}$ En ocasions eren els propis pintors qui subministraven alguns pigments, com el blau d'Acre, que podia trobar-se amb diverses qualitats. La llista de pigments és quasi totalment anàloga als que esmenta, per exemple, Cennini al seu Libro dell arte, tot i que també hi ha d'alguns com l'anyil que no apareixen a l'esmentat llibre. De tota manera, $s^{\prime}$ han classificat en pigments i matèries colorants per ser una mica estrictes amb el seu origen, tot i que, veritablement, els segons solien barrejar-se amb els primers per constituir colors, malgrat que aquestes barreges de productes orgànics amb inorgànics no eren massa duradores ni molt estables a la llum, però el caràcter peremptori i efímer de les construccions justificaven compostos colorants no massa ortodoxos. ${ }^{20}$

El blanc més habitual per a usos pictòrics va ser l'anomenat blanc de plom o 'blanquet'. Aquest carbonat bàsic de plom s'obtenia mitjançant l'oxidació de làmines de plom. Va ser el blanc més emprat en pintura fins la seua progressiva substitució pel blanc de zenc, ja al segle XIX. Tot i que el

\footnotetext{
16 La cola és un material omnipresent als receptaris medievals. Destaquen, com a exemples: CENNINI, Cennino, 1988, pp. 149151, capítols CIV, CX i CXI; CLARKE, Mark, 2011, 118.

17 Vegeu, per exemple: THOMPSON, Daniel V., 1936, pp. 74-188 i 1956, pp. 29-54; RINALDI, Simona, et al. 1986. CENNINI, Cennino, 1988, pp. 64-104; MAYER, Ralph, 1993; DOERNER, Max, 1998, pp. 41-83; CLARKE, Mark, 2001; HUERTAS, Manuel, 2010, pp. 147-174; KROUSTALLIS, Stefanos, 2011 (a) i (b); DIODATO, Sergio, 2012.

18 Un bon estudi sobre els preus dels pigments és el que presenta GARCíA MARSILLA, Juan Vicente, 2011, pp. 71-116. Per a una visió del fenomen una mica més ampla és molt aconsellable l'estudi de KIRBY, Jo; NASH, Susie; CANNON, Joanna (eds.) 2010.

19 GARCÍA MARSILLA, Juan Vicente, 2011, p. 84.

20 Igualment cal tenir en ment que aquestes barreges fins i tot es feien a la pintura comuna de retaules i objectes artístics, doncs, evidentment, la perdurabilitat dels materials sembla ser una qüestió que més aviat preocupa als restauradors que no pas als artistes, cosa que encara es fa palesa avui en dia. De fet, totes les colradures que s'aplicaven sobre els metalls solien ser molt dèbils a la llum, per l'origen vegetal dels seus tints, que permetien transparència. De la mateixa manera les veladures també solien fer-se amb matèries orgàniques precisament per buscar transparència, tot i que, amb el pas del temps, els colors mutaven, s'oxidaven, i canviaven substancialment la seua aparença. No obstant el seu extens ús, alguns pintors teòrics, com ara Cennini, ja desaconsellaven la utilització d'algunes mescles i matèries primeres, fonamentat-se en l'experiència dolenta de les seves aplicacions i la seua ràpida degradació, i aquesta mena de coneixença devia formar part, sens dubte, del conjunt de teories i premisses pictòriques que s'aprenien al taller i que constituirien un coneixement oral que rara vegada es troba posat per escrit.
} 
blanc de calç es coneixia no devia emprar-se fora dels procediments murals. Pel que fa als grocs hi ha diversos compostos que van tenir un paper molt rellevant. En sobresurt l'ocre, un compost a base d'òxid de ferro, de procedència natural i d'aparença terrenca. S'esmenta un 'groch' o 'groguet' que bé podria ser una manera alternativa de denominar al orpiment (un trisulfur d'arsènic potencialment verinós del que també s'enregistren nombroses compres emprant aquest mot concret) o també una forma de referir-se a un groc de plom-estany que ja era conegut des del segle XIII, ${ }^{21}$ tot i que no podem establir de quin dels dos grocs es tracta atès que els dos semblen trobar-se a diverses anàlisis químiques fetes a obres de l'època d'àmbit valencià. ${ }^{22}$ Els rojos minerals més emprats eren el vermelló, o roig de cinabri, un compost de mercuri que s'hi trobava de forma natural o bé s'obtenia per procediment alquímic; 'atzerquó' també denominat mini, un òxid de plom d'un color més ataronjat però intens; i finalment l'almànguena, un òxid de ferro amplament utilitzat fins als nostres dies. Tant el mini com l'almànguena van utilitzar-se també com a ingredients a l'elaboració de 'sises' per a daurar. Pel que fa als pigments blaus, van emprar-se el dos tipus principals que esmenta la documentació als contractes dels retaules: açò és el luxós blau d'Acre (d'ultramar o de lapislàtzuli) i el blau d'Alemanya (o blau d'atzurita) més comú que el primer però amb pitjor consideració, malgrat que sovint en les compres s'indica un 'atzur' però no se'n especifica quin. Tot i que a l'època es coneixia altres blaus, com ara els blaus de plata, ${ }^{23}$ degueren ser els compostos de coure els més predominants, de la mateixa manera que ocorria als verds. Un cas similar podem aplicar precisament per aquest color: tant el verd de malaquita, com el recurrent verd d'aram eren productes derivats del coure; el primer un carbonat d'origen mineral ${ }^{24} \mathrm{i}$ el segon un acetat produït per oxidació de làmines de cúpriques amb vinagre, però de vegades la documentació es refereix a aquests pigments simplement com a 'verdet', malgrat tampoc no s'especifica de quin tipus. ${ }^{25}$ Tots dos es feien servir, però era l'acetat, el verdet d'aram, el més habitual i fàcil de produir. En la documentació apareixen també compres d'un 'verd terrer' que és un pigment de terra, ric en òxid de ferro, allò que en l'àmbit italià es coneixia com 'verdaccio'. ${ }^{26} \mathrm{El}$ darrer pigment que cal esmentar és el negre, i no precisament per l'abundància a les llistes materials: de fet no es menciona en la documentació però el seu ús estava molt estès, i amb tota probabilitat va utilitzar-se també en la confecció de carrosses i escenografies. Si no s'esmenta és senzillament perquè no es comprava, sinó que es fabricava directament molent carbó o recollint el follí, i aquesta era una de les primers coses que aprenien el joves pintors, atès que era un color fàcil d'obtenir a partir de diversos procediments. ${ }^{27}$

Els pigments $s^{\prime}$ havien de molturar finament, ${ }^{28}$ tot i que es venien ja en pols (grosserament molts) o en ocasions en terrossos. Els colors es molien amb l'ajut de l'aigua clara, sobre un taulell de marbre o pedra calcària, mitjançant la fricció amb una moleta troncocònica que solia ser de marbre, o en ocasions pòrfir, serpentina, granit o altres pedres dures i compactes..$^{29}$ La pasta resultant es recollia amb un ganivet pla, com una espàtula, i s'emmagatzemava a petites escudelles vidriades que es tapaven amb

${ }^{21}$ Cennini desaconsella la utilització de l'orpiment i el realgar (trisulfur i bisulfur d'arsènic, respectivament) per la seua coneguda toxicitat i, pel que es desprèn dels seus escrits, preferia utilitzar l'ocre o el 'giallorino', l'esmentat groc de plom-estany.

22 Vegeu: FERRERO, José Luis et al., 2002, pp. 286-293.

23 Sobre el blau de plata vegeu THOMPSON, Daniel V., 1956, p. 154 i RINALDI, Simona, et al., 1995, p. 459.

${ }^{24}$ El verd de malaquita i la atzurita tenen la mateixa composició química $\mathrm{Cu}_{3}\left(\mathrm{CO}_{3}\right)_{2}(\mathrm{OH})_{2}$. Es tracta de carbonats de coure, molt semblants i que, sovint, en la natura es donen conjuntament.

25 Pensem però, que el diminutiu 'verdet' deu referir-se al que en castellà s'anomena 'verdín' i que correspondria, per tant, al verd d'aram

${ }^{26}$ CENNINI, Cennino, 1988, cap. LI, p. 96.

${ }^{27}$ Cennini, per exemple abans de tractar la producció de tots els pigments comença amb els negres. Vegeu: CENNINI, Cennino, 1988, cap. XXXVII, pp. 64-65.

${ }^{28}$ Com més fi era un pigment més superfície específica era capaç de cobrir, i per tant resultava més uniforme en la seua aplicació, però sobretot es rendibilitzava molt més, i més si pensem que, en general, no eren matèries econòmiques. A banda, una pols fina era més lleu i per tant més fàcil d'aglutinar, facilitava la aplicació en capes primes i resultava més estable com a pel.lícula pictòrica, el que implicava que es desprenia amb menys facilitat i que es millorava la seua adhesió al substrat de preparació.

29 Les 'pedres de molre les colós' són molt habituals a la documentació, sobre tot el lloguer i transport de les mateixes als obradors destinats a la confecció del entremesos. Però indubtablement la pedra de moldre colors és un element omnipresent als inventaris valencians dels segles XIV, XV i XVI. Tenim exemples a l'inventari de 1418 de Bartomeu Salset, al de Miquel 
trossos de pell per conservar una certa humitat a l'interior. En aquella època l'ús de la paleta encara no havia acabat de popularitzar-se al sud d'Europa, on per influència de la pintura bizantina i medieval les barreges es feien en escudelletes i vaixelles.

\subsection{Colorants}

A diferència dels pigments, els colorants solien subministrar-los els tintorers, doncs s'empraven fonamentalment per tenyir draps i teles. Tot i això, se'n troben d'altres com ara el safrà o la tinta metalogàlica, que eren objecte de comerç dels especiers, fonamentalment. Com s'ha dit abans, els tints podien barrejar-se amb els pigments per constituir colors semitranslúcids i fins i tot transparents. En general, als receptaris, fins al segle $\mathrm{XVI}$, la interacció de tots dos materials en la preparació de colors és molt habitual, com ocorre, per exemple, al text de Cennini, ${ }^{30}$ Manuscrit Bolonyès, ${ }^{31} \mathrm{O}$ al de Montpeller. ${ }^{32} \mathrm{~A}$ banda de les seues funcions en veladures i colres, destacava el seu ús per a la tinció directa de papers i teles, que constituïa una manera ràpida d'acolorir, amb acabats homogenis. Per regla general els colorants es precipitaven amb alum de roca, ${ }^{33}$ el que permetia fixar-los a aquest substrat, i molt habitualment s'engomaven amb goma aràbiga o altre mucílag per tal de fer-los més duradors davant la humitat.

L'indi 'bagade//34 o indi de Bagdad, i la 'flor de pastell' o anyil, van ser els dos tipus de colorants blaus utilitzats per a la tinció de papers i també per a la consecució de veladures; especialment el primer d'ells. L'indi era molt utilitzat des de la Baixa Edat Mitjana $^{35}$ i en realitat bona part dels blaus foscos en la pintura sobre taula s'aconseguien amb veladures d'aquest extracte vegetal, sobre una base d'atzurita. Els colors violacis podien aconseguir-se de diverses maneres especialment amb barreges de carmí i indi, però hi havia un extracte que oferia la tonalitat violada directament: la orxella. ${ }^{36}$ Malgrat les compres especificades d'aquest producte vegetal també hi ha d'algunes on s'esmenta directament el violeta presumiblement com tint o com a pigment, o el que és més probable, com a una barreja de tots dos. ${ }^{37}$ Precisament va ser el carmí o 'carmini' un dels principals ingredients d'aquestes barreges. Aquesta tintura de color roig intens va tenir una importància clau com a producte de mercat a l'Edat Mitjana i va arribar a ser una matèria d'ampla difusió amb usos tèxtils i artístics, pel seu apreciat color. $^{38}$ Probablement un dels colorants més importants i més valuosos va ser el safrà, subministrat pels especiers, i que tenia, a banda dels coneguts usos culinaris, una gran acceptació entre

Atzuara de 1474 (SANCHIS SIVERA José, 1914, pp. 88 i 126); al del pintor Jaume del Calbo, a 1439, o el de Andreu Garcia de 1452 (MONTERO, Encarna, 2013, pp. 216-219 i 806-850, respectivament), o al de Bertomeu Baró de 1481 (GÓMEZ-FERRER, Mercedes, 2009, p. 89), per posar uns pocs exemples d'una llarga llista.

${ }^{30}$ Les barreges de pigments i colorants són molt habituals a tots el receptaris. Vegeu MERRIFIELD, Mary P., 1967; TOSATTI, Silvia Bianca, 1991; i especialment CLARKE, Mark, 2011, pp. 19-122, qui dedica un capítol a les mixtures de colors i tints.

${ }^{31}$ Ens referim aquí a Secreti per Colori, manuscrit publicat per MERRIFIELD, Mary P., 1967, pp. 325-602.

32 CÓRDOBA DE LA LLAVE, Ricardo, 2005, pp. 7-48.

${ }^{33}$ L'alum de roca es documenta també a les compre, relacionat directament amb la fixació dels tints. Sobre el procés d'obtenció dels tints vegeu THOMPSON, Daniel V., 1956, p. 88; i més recentment KIRBY, Jo; VAN BOMMEL, Maarten; VERHECKEN, André, 2014.

${ }^{34}$ La paraula 'bagadell', deriva de la seua procedència. En castellà trobem el mot 'bagadeo', que sovint apareix transformat en 'macabeo' per deformació fonètica.

35 CENNINI, Cennino, 1988, p. 49. Vegeu també THOMPSON, Daniel V., 1956, p. 135. Sobre l'anyil vegeu també THOMPSON, Daniel V., 1956, p. 138. Vegeu també GARCÍA MARSILLA, 2017, pp. 291-292.

${ }^{36}$ La orxella és el nom que rep un liquen (Roccella phycopsis) del que s'extrau un tint homònim. Es tracta d'una espècie ben coneguda en el món medieval que es recol-lectava, principalment, als penya-segats de les illes Balears i les Canàries. A partir del seu extracte s'hi elabora un colorant de tonalitat púrpura. S'hi documenten compres directes d'aquest extracte als dos documents. Sobre la orgella vegeu: RINALDI, Simona et al., 1983, p. 109, i THOMPSON, Daniel V., 1956, p. 158.

${ }^{37}$ Aquest color es compra directament a Ramon Valls, pintor, així que es molt possible que en realitat es tractés de un preparat fet ad hoc, una pràctica que recull THOMPSON, Daniel V., 1956, p. 159.

38 És molt abundant la literatura sobre aquest colorant i la seua obtenció. Gairebé tots els manuals de pigments, matèries i tècniques artístiques en parlen amplament sobre ell. Hi havia de dos tipus bàsicament, el d'origen vegetal i l'animal el vegetal s'extreia a partir d'arrels de Rubia Tinctorium, i posteriorment pal roig o brasil (el 'brasil' està també documentat a les compres de l'entrada del rei Ferran). Respecte al d'origen animal s'extreia a partir de la polvorització d'insectes dessecats de l'espècie Kermes Vermillio principalment, tot i que també a partir de 1512 va extreure's de diverses espècies de Coccus. Precipitat amb alum de roca s'hi obtenia una mena de pigment que és denominat laca. Vegeu: CENNINI, Cennino, 1998, pp. 71-73; THOMPSON, Daniel V., 1956, pp. 108-111; MAYER, Ralph, 1993, p. 43; DOERNER, Max, 1998, p. 65; RINALDI, Simona et al., 1993, pp. 106 i 114-126. Tots els receptaris medievals contenen receptes de laques. Vegeu especialment MERRIFIELD, Mary P., 1967; TOSATTI, Silvia Bianca, 1991; i CLARKE, Mark, 2011. 
els pintors medievals com a color en miniatures, com a tint per tenyir paper, cuirs i teles ${ }^{39}$ i barrejat amb indi o amb verd d'aram per a la consecució de colors verds vius ${ }^{40}$, tot i que no resultava massa estable en tècniques com el tremp. Tot i això, segons alguns estudis ${ }^{41}$ el seu ús més extens era el d'aportar el color de l'or a colres sobre pans de plata o estany. Per últim cal esmentar la tinta, que també degué ser un recurs important en la consecució de detalls, i que també es recull a les compres.

\subsection{Aglutinants}

Tot i els nombrosos aprovisionaments d'ous ${ }^{42}$ per als pintors que apareixen en ambdós documents, aquests no van ser l'únic aglutinant emprat en la confecció de les carrosses i decorats i, de fet, tampoc constitueixen l'únic tipus de Iligant en la pintura decorativa del moment. Malgrat l'estesa tendència a pensar en el tremp d'ou com quasi la única tècnica pictòrica disponible abans de la popularització de l'oli, cal tenir en compte que hi hagué d'altres productes que acomplien aquesta mateixa funció de vehicles: entre els que cal assenyalar-ne tres més: les coles, l'oli i, especialment la goma aràbiga. D'aquests, exemptant l'oli, tots poden considerar-se també lligants de tremp. ${ }^{43}$

Sens dubte, el tremp d'ou és el més popular de tots els tremps, tant pel seu resultat sedós i vellut. El tremp d'ou podia ser de rovell, de clara o mixt, ${ }^{44}$ tot i que pel que deduïm a la documentació el de clara degué ser el més estès entre els pintors de València, i així ho recullen anotacions com "ous per fer clara per als pintors". ${ }^{45}$ Són tremen- dament habituals les compres d'aquests aliments que esdevenien ingredients imprescindibles de les receptes de colors.

L'ús de gomes i mucílags també està recollit en la documentació de les dues entrades, i era, per descomptat, àmpliament conegut a la pintura medieval. ${ }^{46}$ La goma aràbiga va constituir el principal aglutinant d'aquesta família, i es registren nombroses compres des d'aquesta secreció d'acàcia en tots dos documents, i fins i tot, aquesta s'adulterava amb mel i sucre candi per tornar-la menys trencadissa i fràgil. ${ }^{47}$ Però aquesta goma no va ser I'única utilitzada, de fet, les gomes de fruitals van ser les més comunes entre els pintors, i les més fàcils d'aconseguir, atès que presenten característiques similars a l'exsudat de l'acàcia i no cal importar-les des de territoris llunyans. No obstant això moltes d'aquestes gomes rebien convencionalment el nom de goma aràbiga, malgrat èsser, en realitat, matèries diferents, extretes d'altres arbres més comuns. Però tampoc aquestes gomes eren les úniques: en documentem també l'anomenat 'aiguaxac', que es un mucílag que s'extrau del fonoll, i que juntament amb la goma de figuera, constituïen adhesius secundaris però que també s'empraven, tot i que normalment eren afegits a altres substàncies, normalment colors, per atorgar-les una certa flexibilitat. Les gomes resultaven útils com a vehicles dels colorants vegetals, i la pintura aglutinada amb goma aràbiga era especialment idònia per treballar sobre paper i pergamí, ${ }^{48}$ tot i que, a la pintura al tremp era habitual trobar l'ús de les gomes combinades amb altres lligants.

\footnotetext{
${ }^{39}$ CÓRDOBA DE LA LLAVE, Ricardo, 2005, p. 41.

${ }^{40}$ Aquesta pràctica va ser molt popular fins al segle XVI, i n'és freqüent trobar receptes d'aquestes barreges a diverses fonts, com ara al Livro dell arte (CENNINI, Cennino, 1988, pp. 94-95)

41 THOMPSON, Daniel V., 1956, pp. 186-187.

${ }^{42}$ En el cas de l'entrada del rei Martí es consignen fins a mig centenar de compres d'ous en petites quantitats, d'entre una i quatre dotzenes cada vegada (s'han calculat fins 1.596 ous). A l'entrada del rei Ferran també es conten per milers (CÁRCEL ORTí, María Milagros; GARCÍA MARSILLA, Juan Vicente, 2013, p. 24), tot i que tal i com apunta GARCÍA MARSILLA, Juan Vicente, 2010, p. 89, les compres en el cas de l'entrada del rei Ferran es fan, sovint, al voltant de dos centenars d'ous cada vegada.

${ }^{43}$ Al seu estudi Thompson en recull l'ús dels tres de manera habitual en tota la pintura medieval europea (1956, pp. 54-73) per tant convé prestar atenció a aquests materials que, a banda, es recullen amb freqüència en la documentació al.lusiva a compres de materials artístics en la Corona d'Aragó, i pot ser fins ara no se'ls hi ha reconegut el seu rellevant paper dins la praxi artística.

44 THOMPSON, Daniel V., 1936, pp. 59-63.

45 CÁRCEL ORTí, María Milagros; GARCÍA MARSILLA, Juan Vicente, 2013, p. 263.

${ }^{46}$ L'ús de gomes com a aglutinants era característic de la miniatura, però cal recordar que moltes veladures s'hi aconseguien també amb gomes. D'altra banda hi havia colors que tenien una millor resposta barrejats amb aquests extractes vegetals, com ocorre amb el blau. Vegeu: THOMPSON, Daniel V., 1956, pp. 42-64; KROUSTALLIS, Stefanos, 2011 (a) i (b).

47 THOMPSON, Daniel V., 1956, p. 57. Avui el tremp i l'aquarel.la industrials van aglutinants, de fet, amb goma aràbiga.

${ }^{48}$ Els receptaris dedicats a la miniatura, que són la majoria, en deixen bona constància d'això.
} 


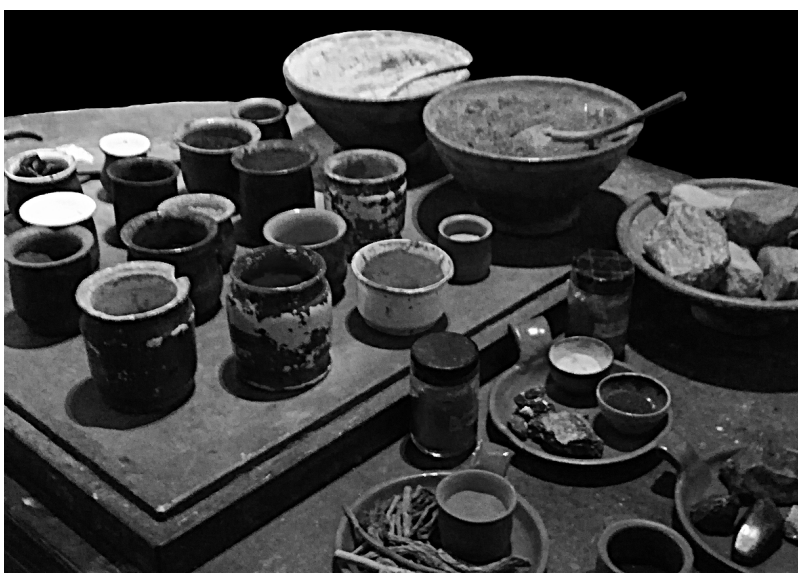

L'oli de llinassa era ja un vehicle pictòric conegut des de l'antiguitat, però la complexa tècnica pictòrica que feia ús d'ell i que es va desenvolupar al llarg del segle $\mathrm{XV}$, primer a Flandes, i desprès a tota Europa, no tenia massa a veure amb els usos que els menestrals i pintors donaven a aquesta substància fins a mitjans de la centúria. L'oli era el producte fonamental d'una de les receptes de 'sisa"49 per daurar, ${ }^{50}$ combinada sovint amb mini i altres assecants. Però, per descomptat, la preparació de 'sises' no va ser l'única funció de l'oli de llinassa. De fet, trobem compres de pigment aglutinat ja amb oli de 'llinós' a l'entrada del rei Martí, com per exemple 'vert $a b$ oli'. ${ }^{51}$ Aquestes barreges apareixen altres vegades en la documentació pictòrica al llarg del segle XV associades amb pintura aillant de superfícies exteriors, i el seu ús ja està documentat com a sistema de policromia de materials petris i lignis al segle XIV. L'oli constituïa un hidrofugant important que creava una pel.lícula setinada i brillant que repel-lia la humitat i segellava les porosi- tats. A més podia constituir també l'element principal de vernissos, o emprar-se tot sol, com a pel-lícula de protecció sobre una pintura aglutinada amb un vehicle magre, ${ }^{52} \mathrm{com}$ la goma o l'ou. ${ }^{53}$ Dos eren, però, els desavantatges que comportava l'ús de l'oli de llinassa: I'elevat temps d'assecat de la pintura -que sovint es solucionava amb l'adició de pigments de plom que afavorien un curat més ràpid-, i la tendència a engroguir-se i ennegrir-se amb el temps, la llum i la pols. Però aquest darrer problema no ho era pas quan es tractava de donar color a estructures $i$ aparellatges efímers, i fins i tot, anys després amb l'arribada de I'oli, aquesta tendència d'envelliment poc o res importaria als pintors.

Les coles van ser un altre important vehicle en la pintura del segle XV. A banda de la 'sisa' comercial que venien els especiers, la pintura amb diversos tipus d'adhesiu era relativament habitual a la pintura medieval. Tant les coles de pergamins, cartílags i ossos, com les coles de peix podien constituir mitjans idonis per aglutinar els pigments, i, de fet, permetien acabats únics de textura càlida que, a més, podien ser brunyits amb posterioritat i no requerien cap tipus de vernís, al temps que s'esdevenien un recurs econòmic i efectiu. El seu major problema era la seua poca estabilitat davant la humitat. Aquests tipus de vehicles solien aplicar-se especialment en pintures decoratives, i per abastir grans superfícies. De fet, el seu ús va ser molt popular fins el segle XVIII per a la policromia de retaules $i$ la consecució de jaspiats $\mathrm{i}$ efectes marmoris, atesa la seua transparència i la capacitat de generar superfícies brillants i poc poroses. També està documentat un extens ús de la cola per temprar alguns colors com ara el blau, ${ }^{54} \mathrm{i}$

${ }^{49}$ La 'sisa' és un terme que en àmbit artístic sol referir-se al mordent utilitzat per a daurar, tot i que en l'àmbit anglosaxó fa referència quasi a qualsevol tipus d'adhesiu. En l'àmbit valencià la 'sisa' podia referir-se a qualsevol dels dos conceptes. Les receptes de 'sises' es troben en tots els receptaris artístics medievals. Al Manuscrit Bolonyès les receptes 160 i 161 (MERRIFIELD, Mary P., 1967, pp. 467-46)

50 THOMPSON, Daniel V., 1956, p. 226; GONZÁLEZ-MARTíNEZ, 1997, pp. 62 i 87; CENNINI, Cennino, 1998, pp. 188-189; GARCÍA MARSILLA, Juan Vicente, 2010, pp. 89-90.

51 'Ítem, comprí d'en Domingo del Port III onzes de vert ab oli, per: I s. VI' (f.127v). ALIAGA, Joan; TOLOSA, Lluïsa; COMPANY, Ximo, 2007, p. 242.

52 CENNINI, Cennino, dedica un capítol a la manera en la que s'ha de preparar l'oli per a pintar al tremp (1998, cap. XCl, p. 136). La preparació d'olis essencials és molt habitual als receptaris tècnics medievals. Per exemple, més enllà dels olis de lli o de nous, prou coneguts a la literatura tècnica pictòrica, al Liber Diversarum Arcium s'esmenten els olis d'oliva i d'ametlles silvestres, per aplicacions transparents amb blaus. CLARKE, Mark, 2011, p. 102. D'aquest mateix autor és molt interessant la reflexió de la p. 84, sobre els olis i l'estat de l'art entre 1400 i 1500. Molt útil resulta també la reflexió de MERRIFIELD, Mary P., 1967, Cap VI, CXV-CCXLV. Aquesta mateixa autora, a la transcripció del Manuscrit Bolonyès, recull la recepta de preparació de I'oli de lli, (1967, p. 488).

${ }^{53}$ Recordem que la pràctica de pintar el cartó pedra amb pintures de diversos tipus i protegir-les amb oli de llinassa encara és una constant en l'elaboració d'escenografies i a València perdura en el món de les falles.

${ }^{54}$ Sobre l'ús de la cola i la goma per temprar el blaus són molt nombroses les al-lusions: CENNINI, Cennino, 1998, pp. 104-105 indica la conveniència de temprar amb cola, El Manuscrit Bolonyès (MERRIFIELD, Mary P., 1967, p. 362) esmenta l'ús de la goma de tragacant, la cola de pergamins, aigua amb goma aràbiga i fins i tot clara d'ou (1967, p. 408). Al Liber Diversarum Arcium s'esmenta el temprat de blau amb clara i amb goma aràbiga. CLARKE, Mark, 2011, pp. 103 i 118. 
com additiu per a reviscolar pigments apagats barrejats en el tremp amb ou. ${ }^{55}$ Les enormes quantitats de compres de 'sisa' i aiguacuits també en podrien estar relacionades directament amb la utilització d'aquests elements com a aglutinants pictòrics durant la confecció de les roques i escenografies, tot i que no podem demostrar-ho de manera empírica, però sabem que els seus usos a la pintura ja eren summament habituals des d'inicis del segle $\mathrm{XV}$.

\subsection{Càrregues estructurals}

Quan ens referim a càrregues estructurals, no ho fem en el sentit pictòric del terme. ${ }^{56}$ En realitat ens referim a substàncies que serveixen com a substrat enduridor, que aporten consistència i plasticitat en l'elaboració d'escenografies.

D'aquestes càrregues el guix amortat, va ser el més important i comú, en tota la praxis pictòrica mediterrània dels segles XIV, XV i XVI. Barrejat sempre amb aiguacuit, constituïa l'element mineral més emprat en la preparació de superfícies de fusta i, de fet, a diferència d'altres Ilocs com a Itàlia on també s'utilitzava el carbonat càlcic, les preparacions hispanes van realitzar-se exclusivament amb aquest sulfat de cal. ${ }^{57}$

També l'algeps, una altra classe de sulfat de calç ${ }^{58}$ barrejat simplement amb aigua va constituir una càrrega per atorgar solidesa a les estructures malgrat la seua major tendència a resultarne fràgil en aplicacions fines. Un del seus usos més estesos en la confecció d'escenografies i roques, a banda de l'obvi revestiment de matèries subjacents va ser el de falcar unions de llistons i bigues, en el que podia col-locar-se amb un reforç d'estopa o tires de drap en superfícies planes, o bé conformant sòlids pegots que ajudaven a immobilitzar les unions d'estructures de Ilistons.

La farina va ser la càrrega principal d'una pasta adhesiva que va denominar-se engrut, i que com la resta de matèries, sota una mateixa nomenclatura albergava receptes diverses que tenien en comú l'ús d'aquest aliment, ${ }^{59}$ i la documentació en recull compres constants per tal d'engrutar, que era una forma alternativa de endrapar amb paper o amb tela i sense guix, -tot i que, en ocasions, el guix sotil podria constituir l'ultima capa d'aparellat sobre l'engrut, per afavorir un pintat més homogeni i una major resistència estructural.

\subsection{Mordents i vernissos}

Altres productes d'ús comú que responen a fórmules ben variades en la producció artística i queden enregistrats a les compres de 1402 i 1414 són les 'sises de daurar' o mordents, i els vernissos. Les 'sises' comercials per a daurar, que es compraven als especiers i també als propis pintors, eren una mena d'adhesius o mordents dels que en desconeguem la seua composició exacta, tot i que la seua base era un adhesiu, generalment proteic. Sabem que en alguns tipus de 'sisa' de daurador s'hi afegia l'oli i d'altres productes com el mini. Als manuscrits i receptaris dels segles XIV i XV, són tan abundants com variades les receptes d'aquestes 'sises', i sembla no existir una homogeneïtat en les seues composicions. ${ }^{60}$ Algunes incloïen ous, alls, diversos mucílags, extracte d'àloe, resines, gomes, olis, sucre o mel, a banda de coles proteiques. Molt similar és el que ocorre amb els vernissos, que eventualment també apareixen ja elaborats a les compres, i dels que tampoc no resultaria gairebé fàcil esbrinar-ne la seua composició. ${ }^{61}$ Els receptaris com mencionen molts tipus de vernissos $i$ mordents per a l'or, i la seua diversitat els fa ele-

\footnotetext{
55 THOMPSON, Daniel V., 1956, p. 58.

56 En aquest sentit les càrregues són additaments que s'afegeixen a la pintura per tal d'atorgar-li consistència, o poder per cobrir i hi poden afegir-se tant als pigments com als colorants.

57 MAYER, Ralph, 1993, pp. 330-331.

58 Per a la diferència entre tots dos vegeu MATTEINI, Mauro; MOLES, Arcangelo, 2001, p. 53.

59 CENNINI, Cennino, 1988, p. 146.

60 Un bon exemple d'aquesta premissa és contrastar les diverses composicions recomanades per les fonts. Al Manuscrit Tabula Imperfecta, de Jean Le Beghe, les receptes 138, 139 i 210 (MERRIFIELD, Mary P., 1967, p. 44); De Coloribus Faciendas (S. Audemar), receptes, 191-193 (MERRIFIELD, Mary P., 1967, pp. 152-156); De Coloribus Diversis Modis Tractatur (Ms. Alcherio), receptes 291-292 (MERRIFIELD, Mary P., 1967, pp. 258-269); Al Segreti per Colori, més conegut com Manuscrit Bolonyès les receptes 160 i 161 (MERRIFIELD, Mary P.,1967, pp. 467-476); Al Liber Diversarum Arcium, recepta 32 (CLARKE, Mark, 2011, p. 132); al Llibre de I'Art, CENNINI, Cennino 1998, caps. CXXXI-CXXXIII, pp. 166-169 també dedica al bol i a les sises algunes consideracions.

61 Gianbattista Armenini comenta al seu tractat que els vernissos més vells es feien amb resina d'avet, i que per facilitar-ne la seva aplicació era recomanable deixar l'obra exposada al sol. ARMENINI, Gianbattista. De'veri precetti della pittura, 1587, Llibre II, Cap. IX. Altres fórmules esmenten la resina de juniperus (sandàraca) o encens. Vegeu MERRIFIELD, Mary P., 1967, caps. CCLXXV-CCXXX, pp. 488-489.
} 
ments de difícil estudi. ${ }^{62}$ Es sap que per a fer vernissos, per exemple, a més de l'oli, podien emprar-se ceres, coles, gomes, resines, essències i diversos esperits, com ara el del ginebre. Tot i que sembla que van existir els vernissos comercials, el més lògic és que el vernís es preparés ad hoc, en funció de la superfície que es volgués envernissar, i que es preparés en la quantitat necessària per evitar la seua ràpida degradació.

\subsection{Làmines metàl·liques}

Més important encara va ser l'ús de les diverses làmines metàl-liques de or (pur o partit), plata, i menys habitualment fulla d'estany, que proporcionaven els batifulles en comandes de centenars $i$ milers. Aquests artesans van treballar amb eficiència per poder donar resposta a les enormes quantitats de pans comanades pels pintors i menestrals. A l'entrada del rei Martí s'han calculat que, almenys, van utilitzar-se 14.019 pans d'or fi, 6.950 d'or partit i 13.500 pans de plata (90 motlades), tot $\mathrm{i}$ que hi ha alguns pagaments que per anar combinats amb altres materials no ens permeten calcular la quantitat exacta de pans utilitzats, el que implica que probablement es degueren emprar quantitats encara majors. A l'entrada del rei Ferran, per la seua part, van subministrar-se 15.115 làmines d'or (concretament 8.960 del fi i 5.515 del partit), a més de 1.200 pans de plata, ${ }^{63}$ xifres lleugerament menors que en el cas del seu predecessor, però que en ambdós casos suposen quanties econòmiques molt elevades per a la construcció d'aparells efímers. Una data que crida l'atenció és que, malgrat la transitorietat de la festa, l'or partit no va ser ni de lluny el més utilitzat en cap dels dos casos. Els pans d'or fi i argent no van escatimar-se, tot i que anaven a ser aplicats en estructures passatgeres que tan sols serien utilitzades una sola vegada.

\subsection{Papers}

Les compres de paper resulten summament habituals en la documentació, tant de la 'ma gran' com de la 'ma xica', en ocasions 'toscans', 64 i en ocasions de Xàtiva. ${ }^{65}$ Es compren també papers vells ja usats, 'per obs engrutar', i se'n tinyen de nous per tal de fer flors de colors, una feina que solien fer els tintorers, a banda d'aquells papers que es compren per dibuixar o escriure. El paper adquireix així un protagonisme destacat en la confecció dels entremesos, amb utilitats ben diferenciades, esdevenint-se un altre dels veritables protagonistes de la festa. Cal en aquest punt assenyalar l'enorme tradició paperera que pervivia a València des d'època islàmica, i sense la que no pot explicar-se aquest veritable protagonisme. ${ }^{66}$

\subsection{Fustes}

La fusta va ser, sens dubte, el material més abundant d'entre els emprats, tant pels seus usos estructurals i de bastiment, com d'acabats directes i indirectes. S'enregistren moltes compres de fustes dels més diverses mides i natures (carrasca, pi, alber, xop, taronger, boix, faig roure, om, etc.). Els artesans $\mathrm{i}$ fusters consideraven aspectes com la seua duresa, la flexibilitat, la resistència estructural, la resistència al clima, la facilitat de tallat, i altres aspectes que feien que es decantessin per una o altra espècie en funció de la utilitat que es deparés per a cada peça.

\subsection{Altres elements (plomes, teles $i$ altres ornaments)}

La diversitat de tècniques i acabats necessaris feren que la llista de materials utilitzats en la confecció de disfresses, ornaments, decoracions, estendards, palis, penons, etc. es multipliqués exponencialment. En aquest sentit és necessari advertir que hi ha moltes matèries naturals i processades que passaren a formar part intrínseca de la desfilada i dels seus components: teles de tots els tipus, oripells, pells, aludes, fils de metalls preciosos, filferros, claus, perns metàl-lics i utillatges, fustes tallades, cornamentes, plomes, ales d'àguila, coles de cavall, etc. No ens detindrem més en aquests materials perquè considerem que el seu paper és més aviat accessori dins el tema que en ocupa en aquest treball, i lògicament com a materials 'artís-

\footnotetext{
62 Sobre el vernissos és interessant destacar l'absència de formulacions a la majoria de receptaris anteriors al segle XVI. Hi trobem mencions al manuscrit Experimenta de Coloribus, tot i que no es desenvolupen formulacions concretes (MERRIFIELD, Mary P., 1967, pp. 94-95); al Manuscrit Bolonyès (MERRIFIELD, Mary P., 1967, p. 520); o al Llibre de I'Art, CENNINI, Cennino, 1998, caps. CLIV,-CLVI, pp. 192-194.

${ }_{63}$ GARCÍA MARSILLA, Juan Vicente, 2010, pp. 82-83.

${ }^{64}$ El paper toscà designava, de manera genèrica, diversos tipus de paper importats d'Itàlia, principalment de Gènova.

${ }^{65}$ Precisament Xàtiva, o 'Exativa', com també apareix a la documentació, va ser un dels grans productors paperers a la Corona d'Aragó. Vegeu: VENTURA, Agustí, 1990, pp. 123-142.

${ }^{66}$ Veure, per exemple AL-ABBADI, 2005.
} 
tics' o més aviat 'tècnics' no presenten major rellevància, malgrat que estèticament desenvoluparien un paper notable en adquirir un cert protagonisme visual.

\section{Procediments}

Pel que fa a les metodologies de treball, el primer que cal assenyalar és que no disten en absolut del conjunt de procediments que s'empraven a les disciplines artístiques del moment, trobant analogies entre la pintura de mobles (caixes i retaules) principalment, la miniatura i la pintura decorativa sobre tela (cortines i draps). En realitat el que fan els artesans és utilitzar els procediments que coneixen, ${ }^{67}$ i no inventen cap tècnica nova. La veritable aportació és deixar per escrit els materials i la nomenclatura dels procediments, el que ens permet rastrejar-los i verificar-los, i sobre tot ens facilita la relació entre les matèries constitutives i els usos que d'elles es feien.

\subsection{Imaginacions, mostres, dissenys}

El pas inicial per poder dur a terme la confecció de les carrosses o roques i les diverses escenografies era imaginar i projectar el conjunt d'artificis que composarien la desfilada. Aquí convé separar dos tasques creatives: d'una banda la projecció intel-lectual i temàtica, que sovint no escatimava cap detall, i que solia recaure en figures de l'àmbit de la cultura o l'Església, i d'altra banda la plasmació o materialització de les idees conceptuals per tal de transformar-se en objectes tangibles. Però abans de dur a terme la construcció de cap artefacte calia projectar-la amb paper, tant per a que l'artífex intel-lectual pogués veure plasmada la seua idea i donar el vistiplau com per a fer intel-ligible aquesta idea als nombrosos artesans que hi participaven. Un treball tant sustentat en la mútua col-laboració de menestrals de diversos oficis requeria unes directrius ben detallades amb plànols o esquemes on tot quedés especificat, i aquesta era una de les tasques dels pintors imaginers que utilitzaven la seua habilitat en el dibuix per tal de descriure les solucions pensades prèviament. En aquest cas es feien servir papers de mostra -com a la resta de les disciplines i procediments artístics- ${ }^{68}$ que eren la millor manera d'explicar als altres menestrals com havien d'operar. Malauradament no conservem cap d'aquelles mostres, però segurament es tractés d'esquemes, plànols i figuracions, detalls de maquinària, etc., realitzats amb carbó, tinta o estil de plom o plata sobre paper, i on probablement s'hi van representar les carrosses, disfresses i aparellatges que hi van intervenir a les respectives cavalcades. Queda constància, però, de la seua existència als pagaments fets als pintors. ${ }^{69}$

\subsection{Adaptació de carros, construcció de ca- dafals, estructures escenogràfiques $i$ confecció d'enginys, maquinàries $i$ auto- matismes}

El primer pas per a la construcció de les roques i carrosses que hi participarien a la desfilada, un cop elaborats els respectius dissenys, era aprovisionar-se de carros i carretes que suposarien el xassís mòbil sobre el que es bastia tot l'entramat escenogràfic. Cada entremès podia dur vàries carrosses i cadascuna d'elles havia de ser preparada a consciència amb nombrosos processos que implicaven a diversos artesans, començat, lògicament pels fusters, que a més eren els encarregats de preparar cadafals, umbracles i altres estructures urbanes, a banda de bastir les escenografies.

Una figura veritablement assenyalada és la del mecànic, que ja apareix ressenyada així a la documentació. Moltes de les roques comptaven amb automatismes i mecanismes que permetien la mobilitat de determinades parts. La majoria d'aquests ressorts funcionaven per transmissió energètica, mitjançant jocs de politges simples i compostes, com els polispastos, les politges de transmissió per corretges, les combinacions de politges amb rodes dentades i cargols sense fi, o els torns; mecanismes que eren sobradament coneguts en el món naval en l'àmbit de la construcció, en l'àmbit de la maquinària bèl-lica i en els mecanismes industrials com els molins, trapijos, torns, etc., ja

\footnotetext{
${ }^{67}$ Els processos canvien molt poc a poc, i fins i tot, la tradició de elaboració tècnica de les roques no ha canviat, essencialment, gairebé fins al dia d'avui, tot i que el mercat dels materials s'ha expandit oferint-nos solucions més durables $i$ en molts casos econòmiques. Aquesta analogia pot veure's també fins i tot a la construcció de falles: no ha sigut sinó en els últims 30 anys quan la lleugeresa dels materials escumosos (poliuretà i polietilè) han anat desplaçant els materials tradicionals.

${ }^{68}$ Sobre la 'mostra' en l'àmbit artístic de la Corona d'Aragó i la seva rellevància cal veure MONTERO, Encarna, 2004; BAZZOCCHI, Flavia, 2009, pp. 281-294; MONTERO, 2013 (a), pp. 85-163; MONTERO, 2013(b) pp. 55-76; IBÁÑEZ, Javier, 2014, pp. $305-328$

69 'Primo, pos en compte de data, los quals de manament dels honorables jurats de la ciutat de València doní a.n Vicent Çaera, I dels maestres de la dita obra en paga de diverses treballs per ell sostenguts en imaginar en les invencions de la dita festa e altres treballs extraordinaris ultra los diornals dessús specifficats, vint florins' (f. 131r.). ALIAGA, Joan; TOLOSA, Lluïsa; COMPANY, Ximo, 2007, p. 246.
} 
des d'època Andalusí. ${ }^{70}$ Les politges queden documentades a les compres, com també els torns i fins i tot es fabricaren cargols específics. Això propiciaria que hi haguessin carrosses amb elements giratoris, basculants o pivotants. La energia era proporcionada fonamentalment per transmissió des dels eixos de les rodes dels carros, -que podien reforçar-se si calia, tot $\mathrm{i}$ augmentat el seu nombre-, així que mentre la carrossa avançava també s'hi mourien els seus automatismes, que aturaven quan aquesta detenia la seua marxa. Els mecanismes es lubricaven amb sèu, del que també n'abundaren les compres. La instal.lació de tots els esmentats maquinaris podia suposar una modificació estructural absoluta dels carros, com també ho podia suposar l'alçament d'elements escenogràfics i ornamentals al sobre d'ells. L'estructura interna de les roques devia ser semblant a la de les embarcacions, amb quadernes perimètriques, a banda dels eixos centrals, que conferien una disposició molt semblant a les estructures de les barques i naus, que permetia repartir el pes de manera homogènia. Aquesta disposició sembla mantenir-se en els exemples que conservem a partir de $1512 .{ }^{.1}$ Cadascun d'aquestos elements lignis es realitzava, com s'ha apuntat amb anterioritat, amb un tipus de fusta diferent, amb fustes dures d'espècies frondoses per a eixos i bastiments estructurals, i altres més fluixes com les de pi, per a altres elements decoratius. ${ }^{72}$

\subsection{Construcció d'armadures i bastiments}

L'estructura més sòlida que servia per sostenir la resta de l'esquelet es feia amb bigues. Tot plegat, la construcció d'armadures i bastiments es feia amb posts, taulons que es serraven per obtenir llistons, que eren clavats amb diversos tipus de claus, clavons i ancoratges per conformar bastiments estables que poguessin suportar una carcassa exterior rígida o semirígida i relativament lleugera, i també el pes de les persones que hi anaven al sobre. La cola, les cordes, les trenyelles i l'algeps hi jugarien un paper fonamental, a banda de la mencionada ferralla, a l'hora assegurar i refermar totes aquelles estructures lígnies.

Un detall interessant sobre la construcció de les roques és la utilització de les anomenades 'rodes d'ariscles'; xapes de fusta primes, d'avellaner o freixe, fàcils de doblegar, que es compraven ja arrodonides als sedassers i que permetien la confecció d'estructures orgàniques i corbes, sobre les quals es dipositaria després el cartó-pedra, el paper amb engrut o els draps engrutats o enguixats que adquirien una aparença pètria, i que donarien segurament pel seu aspecte, nom genèric $a$ aquest tipus de carrosses. Fins i tot s'empraren aquests cèrcols per a la construcció de la boca de la cova d'una de les roques de l'entrada del rei Martí, aprofitant la seua capacitat de blegar-se, ${ }^{73}$ i la seua resistència. De fet, a la documentació s'especifica en molts casos la utilitat que se'ls hi va donar a aquestes xapes de fusta, 'per a obs de fer les roques'.

\subsection{Elaboració de motlles}

Els motlles eren un recurs imprescindible per a la seriació d'elements tridimensionals, i com encara ocorre al món faller, permetien obtenir formes volumètriques primes i lleugeres, en dipositar paper engrutat, o amb guix, en fines capes al seu interior. Els motlles de peces petites i ornamentals solien ser de fusta o bé de guix mateix, reforçats amb estopa i drap. Solien ser motlles senzills, d'una peça, o bé bivalves. Podien fer-se a prenent un objecte existent, o també partint d'un modelat amb fang. La seua poca complexitat no permetia una gran precisió de detalls, que sovint eren reelaborats sobre l'objecte buidat, tot i que també existien els motlles perduts, que sols podien utilitzar-se en una única aplicació, però que permetien un major registre. A la documentació hi ha compres de guix o algeps explícitament per fer motlles. Aquests utensilis constituien un recurs de taIler molt important, ben conegut pels pintors, tal i com ja ho evidencia fins i tot Cennini. ${ }^{74}$ Però, a

70 Un petit marc contextual sobre tecnologia i enginyeria mecànica a l'Edat Mitjana hispana són ressenyables els estudis de VERNET, Juan, 1993, pp. 46-50; ZOZAYA, Juan, 1994, pp. 43-60; HILL, Donald, 1994, pp. 22-28; i molt especialment CÓRDOBA DE LA LLAVE, Ricardo, 2008; i per últim SIERRA, Carlos, 2011, pp. 40-49.

71 SIMÓN, José Manuel; VIVANCOS, María Victoria; GRAFIÁ, José Vicente, 2010, p. 70.

72 Aquest fet també s'ha pogut comprovar en els exemples conservats datats a l'inici del segle XVI, que es custodien en la Casa Museu de les Roques del Corpus Christi, a València.

73 'Ítem, comprí tres cèrcols d'avellaner per a la cova de la rocha, per preu de: II ss.' (f. 133v.). ALIAGA, Joan; TOLOSA, Lluïsa; COMPANY, Ximo, 2007, p. 252.

74 El text de Cennini de fet és pràcticament l'únic que esmenta aquestos processos escultòrics. L'autor no escatima en capítols dedicats a aquestes tècniques CENNINI, Cennino, 1988, caps. CXXVII-CXXVIIICLXXXI-CLXXXIX, pp. 164-165, i 226-235. També hi trobem la recepta d'una pasta per fer motlles al Segreti per Colori, més conegut com Manuscrit Bolonyès, recepta 197 (MERRIFIELD, Mary P., 1967, p. 484). 
més, s'han documentat casos de motlles conservats relacionats amb la producció de màscares i altres elements festius a l'àmbit valencià. ${ }^{75}$ Els positivats podien fer-se amb paper maixé, paper engrutat, escaiola reforçada amb draps o estopa, cera, argila, etc., normalment amb la tècnica d'estratificat. ${ }^{76}$ Per evitar l'adhesió del positiu a la matriu podia emprar-se sèu o diverses classes d'olis i essències que funcionaven com a lubricant separador i desemmotllant. En assecar-se el contingut del positiu, aquest experimentava una mínima retracció o encongiment que també facilitava la seua extracció del motlle. Les peces obtingudes a partir de motlles podien ser, des de carasses i petits elements, fins a peces d'una major envergadura, grans ornaments, caps de monstres, etc. ${ }^{77}$

\subsection{Elaboració de coles}

L'elaboració de coles era una de les tasques més comunes en els tallers i obradors de fusters, tapiners, caixers, imaginaires, pintors, etc. Com s'ha dit abans la cola més utilitzada era la de pells, de vedella, conill i de cabrit principalment. Per a elaborar-la es deixaven a remulla pedaços de pergamins i pells de diversos animals en una gran cassola o olla durant tota una nit i després es feia bullir fins que el seu volum disminuïa a la meitat o fins i tot a un terç si es desitjava més forta. Després es tornava a deixar en repòs tota una nit, es trascolava i es distribuïa a safates per treure'n pans o plaques, que una vegada seques podien tornar a hidratar-se recuperant el seu estat líquid i el seu poder adhesiu. Tota aquesta feina era una de les tasques que solia recaure en els ajudants de taller, mossos i oficials. La cola podia adquirir-se ja dessecada o bé, més habitualment es compraven els pergamins o els trossos de pell, que en els dos casos que ens ocupen solia subministrar el pintor Domingo del Port. Aquesta cola orgànica es feia malbé molt de pressa i es descomponia o s'avivava amb fongs i floridures emetent una forta pudor. ${ }^{78}$ Una de les fórmules per allargar la vida útil dels aiguacuits proteics i evitar la seua ràpida descomposició -independentment de la seua naturalesa- era afegir una mica d'amoníac, ${ }^{79}$ sal que també es documenta a les compres i que, amb quasi tota probabilitat s'utilitzava com a additiu conservant, molt possiblement Iligada a la producció d'aquests adhesius. Com s'ha apuntat abans, les coles van tenir usos ben diversos però de màxima rellevància, tant en la producció de pintures, com en l'adhesió d'elements, però on més van intervenir, sens dubte, va ser en I'aparellat inicial dels suports i en la fabricació d'engrutats i gessos.

\subsection{Engrutat}

L'engrut o cola de farina també respon a formulacions diverses. Hi ha de dos tipus bàsicament, el que sols conté aigua i farina -on el poder adhesiu recau en el midó- i el que, a més, suma l'esmentada cola de pells com a aglutinant principal, que degué ser, amb probabilitat, la variant més utilitzada als obradors valencians, atesa la seua major resistència estructural i perdurabilitat. És possible que l'amoníac també s'utilitzés per desinfectar aquestes pastes. L'engrut en sí mateix es una pasta adhesiva que ha de menester aplicar-se arrebossant elements o formant una conglomerat amb ells.

L'engrutat requereix doncs alguna mena de fibres que eviten el seu despenjat en superfícies de tendència vertical, i al mateix temps es busca que aquest adhesiu confereixi duresa a les esmentades fibres. Pot fer-se amb paper, o també amb tela, tot i que per aquesta és més aconsellable el guix.

\subsection{Paper maixé, i cartó-pedra}

Lligat de manera directa a l'engrut, i tal vegada perquè també aquest era un element fonamental d'aquesta mateixa tècnica artística, està el que avui es denomina papier-maché o paper maixé, que va ser el que amb més freqüència va conformar la pell de les carrosses i roques. A Itàlia la tèc-

\footnotetext{
75 Vegeu el cas dels motlles de màscares castellonenques a ZARAGOZÁ, Arturo, 2017, pp. 79-84.

${ }^{76}$ Aquesta tècnica, encara utilitzada avui, permet obtenir objectes buits per dins, i no macissos. A diferència del positivat per col.lada, el buidat es fa dipositant una capa fina d'una matèria determinada, amb un gruix que pot oscil.lar entre uns pocs mil.límetres i uns pocs centímetres, evitant així el malbaratament del material i aconseguint-ne una lleugeresa molt major que sí l'objecte fos massís. Encara s'utilitza, per exemple, en l'àmbit faller, on els 'ninots' són elaborats en motlles, a les parets dels quals es diposita el cartó pedra. COLOMINA, Antoni, 2017, p. 110.

77 És inevitable establir paral-lelismes amb altres disciplines d'escultura efímera que perduren a la tradició artesanal valenciana: des de la confecció de caps i ornaments per a festes com el Corpus, a la producció artística fallera. Per a tots dos casos els motles encara avui perviuen com a eines fonamentals del procés.

78 Cennini recomana fer-la en hivern, quan fa molt de fred, precisament per evitar açò (1988, cap. CIX, pp. 149-150).

79 HUERTAS, Manuel, 2010b, p. 19.
} 
nica es coneix com cartapesta, ${ }^{80}$ terme que acull tant el paper maixé com l'anomenat cartó pedra. Es tracta d'un procediment que té orígens asiàtics, i que els musulmans de la península ja devien conèixer, donat que la producció de paper era una de les seues especialitats. Atès que es tracta d'un material molt fàcilment degradable, poc estable i associat a artesanies efímeres no $s^{\prime}$ han conservat gairebé mostres d'aquella època, ${ }^{81}$ més enllà dels esmentats casos de les Roques del Corpus Christi valencià que daten ja d'inicis del segle XVI, i on s'hi troben alguns elements fets amb paper encolat o cartó, com ara dimonis i altres decoracions, ${ }^{82}$ tot i que a nivell escultòric conservem la imatge de San Miquel de l'Ajuntament de València ${ }^{83}$ i la primera imatge de la Verge dels Desamparats. ${ }^{84} \mathrm{El}$ fonament del procediment consistia en trossejar fulls de paper i esmicolar-los; a continuació s'ameraven amb l'esmentat engrut i podien modelar-se amb les mans o bé aplicar-se en fines capes dins de motles. Opcionalment també podien amerar-se fulls grans de paper sencers, que després eren deixats caure formant irregularitats i plecs sobre bastidors de fusta, tot i adquirint un aspecte similar al de les formacions rocoses. Quan aquesta mateixa tècnica es combina amb guix o escaiola rep el nom de cartó pedra. El sulfates de calç endureixen la superfície conferint-ne una major resistència mecànica, afavorint el pintat. ${ }^{85}$ Tot i que no podem saber amb exactitud la formulació concreta de l'engrut, ${ }^{86}$ és molt possible pensar que tot anés recobert per, almenys, una sotil capa d'estuc de guix, que inclús podia anar barrejada amb cola, per segellar qualsevol porositat i atorgar així una major duresa.

\subsection{Enguixat}

L'enguixat era, en termes artístics, un procediment fonamental, lent, però que garantia resultats bons si es feia a consciència. Era un procés comú sempre que hi havia un acabat pictòric sobre un objecte fusteny: mobles, caixes i retaules, i per descomptat, roques i escenografies. Sabem, pels contractes de l'època que es donaven vàries mans de guix gros, i després altres tantes de guix prim, sempre barrejat amb aiguacuit per aportar una major duresa i una menor tendència a esquerdarse. ${ }^{87}$ El guix, com l'algeps i la farina, es sedassaven per eliminar impureses i grums, i es barrejaven amb l'aiguacuit, conformant un estuc orgànic/inorgànic que preparava la superfície per rebre la capa pictòrica. ${ }^{88}$ S'aplicava sobre un aparellat inicial de cola, i sovint comportava l'endrapat, que era la preparació de la superfície de fusta amb draps de Ili, estopa, tires de tela o pergamí. Sobre una superfície de paper engrutat o cartó pedra,

${ }^{80}$ Als territoris del sud d'Itàlia és on es documenta, en segon lloc, aquesta mateixa tècnica, tot i que allí se'n té constància des de la segona meitat del segle XV, arribant a popularitzar-se ja a partir del 1500. Vegeu: ROSSI-RÒISS, Enzo, 1983. És possible que el seu origen en la península itàlica pogués estar en relació amb l'expansionisme de la Corona d'Aragó a partir de les conquestes d'Alfons el Magnànim, com a part de la koiné d'influències a la Mediterrània, que ja és matèria d'estudi (vegeu COMPANY, Ximo, 2009, pp. 15-50). Durant el segle XVII aquest procediment va popularitzar-se a terres italianes, tot i esdevenint un procés auxiliar en escultura. Vegeu, per exemple: LÓPEZ CONDE, Rubén, 2011, pp. 211-226. No obstant a la resta d'Europa aquesta tècnica no va tenir massa acollida (paradoxalment en un inici sembla estar lligada a territoris amb tradició paperera), però finalment va gaudir d'un cert període de moda a França i especialment a Anglaterra cap a mitjans del segle XVIII.

81 MONTERO, Encarna, 2017, p. 100.

82 SIMÓN, José Manuel; VIVANCOS, María Victoria; GRAFIÁ, José Vicente, 2010, p. 70.

83 SARRIÓ, Ma Francisca; JUANES, David; FERAZZA, Livio, 2017, pp. 9-24.

84 GARCÍA, Greta; ROMÁN, Rosa María, 2017, pp. 147-160; MONTERO, Encarna, 2017, pp. 99-119.

${ }^{85}$ A la Corona d'Aragó la tradició de l'ús d'aquesta tècnica resulta obvia: les carrosses i roques de la processó del Corpus Christi de València, els caps i estructures de gegants i cabuts aragonesos, les cucaferes catalanes, i fins i tot les falles o les fogueres de Sant Joan. Evidentment totes aquestes manifestacions tenen orígens diversos, però el que resulta anàleg a totes elles és la pervivència d'una tècnica artesanal de caire marginal, fonamentada en la tradició i que no ve recollida als manuals de tècniques artístiques.

${ }^{86}$ Els engrutats de paper amb coles orgàniques i farines constituïen un mos suculent per a les rates, que proliferaven a les drassanes.

87 Als contractes de retaules és habitual trobar-se amb el terme 'enguixat', i són molt nombrosos els casos documentals que així ho testimonien, alguns fins i tot especificant guix prim i gros: "(...) síe tengut de encolar, emplastar, endrapar e enguixar, de bon guix, gros e prim, lo dit retaule (...)", o "(...) que los pintores ayan a yngueexar todo el retaulo dos vezes de guix groso, y dos de guix primo muy bien temprado porque salga el oro muy ardient en los camperes (...)". CALVO MANUEL, Ana María, 2006, pp. 21-22.

${ }^{88}$ Vegeu, sobre l'enguixat els capítols de CENNINI, Cennino, 1988, pp. 150-159, caps. CX-CXXI. Els receptaris medievals no solen entrar en aquest tipus de preceptes tècnics que s'allunyen de la recepta en sí; és per això que són molt escasses les al-lusions als enguixats en receptaris o tractats anteriors al segle XVI. No obstant, trobem algunes receptes, com ara al Segreti per Colori, més conegut com Manuscrit Bolonyès, amb els nombres 206 i 207, per exemple (MERRIFIELD, Mary P., 1967, pp. 488-490). Vegeu també de la mateixa autora, CCLXXXI-CCLXXXII. 
l'endrapat es feia innecessari, però degué utilitzar-se sobre altres superfícies de fusta, com taulons d'escenografies i panys de carros, atès que es compren nombroses vegades draps vells 'per obs d'endrapar'. El moment de l'enguixat era crucial per dissimular desperfectes i millorar les formes. També era durant aquell procés quan es feien els anomenats embotits ${ }^{89}$ en les parts que s'havien de daurar i que duien una certa decoració en relleu. El procediment acabava raent una mica les formes i anivellant tots el plànols per deixar enllestida la superfície de cara a l'aplicació pictòrica.

\subsection{Daurats}

Abans, però, de donar color a les formes s'havien d'aplicar els pans metàl-lics de les partes daurades o argentades. L'or i la plata eren part dels fastos dels que feien gala carrosses i ornaments, i a les entrades dels respectius monarques hi van tenir un protagonisme ben palès. Per a l'aplicació dels pans solia preparar-se la superfície amb una capa de bol d'Armènia o 'bolermini', al sobre de la qual s'aplicava una 'sisa' o mordent, generalment a l'aigua, tot i que en ocasions s'hi aplicà també una 'sisa' d'oli de llinassa amb mini. Hi existiren diverses formulacions d'adhesius per enganxar els pans metàl-lics, que sovint podien incloure altres elements com sucre candi, mel, o alls, com ja s'ha apuntat al corresponent apartat dels materials. El daurat solia comportar, a més, altres procediments d'acabat relacionats amb aquesta tècnica, com són l'esmentat embotit, els granejats, punxonats i repicats, i fins i tot els esgrafiats i colres. Per últim cal esmentar que també s'hi documenten compres de materials auxiliars específics per a aquestes tasques de daurat, com les adquisicions de cotó per als dauradors, que s'enregistren en el cas de l'entrada del rei Ferran. Aquest material era fonamental per tal d'asseure la fulla d'or sobre el substrat adhesiu, i el cotó permetia exercir una lleu pressió, sense fer malbé l'or.

\subsection{Pintura}

Pel que fa a l'aplicació pictòrica del color cal asse-

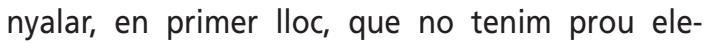
ments a la documentació per establir-ne un mètode homogeneïtzat. Més aviat, una de les grans evidències que aporten els documents de compres de les entrades dels dos monarques a València és que, per la varietat de materials, pot intuir-se que la diversitat dels procediments pictòrics i la barreja de tots ells degueren ser una constant. I això pot ser deuria fer-se extensible a la pintura de retaules i objectes artístics en aquells moments. $\mathrm{Si}$ atenem als principals receptaris de l'època -Manuscrit de Bolonya i especialment /l libro dell Arte de Cennini- ja es pot observar que es recomana un tipus de temprat diferent en funció de cada color, i s'adverteix que no tots són vàlids per a totes les tècniques. Fins $\mathrm{i}$ tot Thompson, als seus estudis de recerca en les tècniques medievals pictòriques (1936 i 1956) alerta al lector, quan en parla del tremp, de que les barreges entre diversos aglutinants eren comunes. ${ }^{90}$ Així, per exemple, un tremp de clara d'ou, podia contenir rovell per alguns colors, i també podien coexistir tremp de caseïna, de cola i de goma en una mateixa taula. Al sobre, la tècnica pictòrica implicava també l'ús de veladures i colres, que de vegades es feien amb mitjans greixosos o resinosos. ${ }^{91}$ En general, si atenem a les diverses compres de materials on s'esmenten els ous, les gomes i l'omnipresent aiguacuit, intuïm que el major predomini el van tenir les tècniques pictòriques a l'aigua, de la família dels tremps. Aquests processos permetien un ràpid assecat de la pel-lícula pictòrica, que era avantatjós per poder solucionar de manera expeditiva la abundant comanda d'estructures i complements escenogràfics que calia pintar. Òbviament, la tècnica també tenia les seues limitacions, doncs no permetia la fusió de colors amb facilitat, i podia fer-se malbé amb la humitat. El procés de pintura començaria cobrint amb bases de color els principals volums, i pintant-ne al damunt, llums, ombres i tot tipus de detalls, amb pinzells al sec i fins $i$ tot amb colres o inclús veladures amb olis assecants. La entonació inicial podia recaure en mans d'oficials i aprenents, com tants altres processos ja esmentats, però la consecució d'un cromatisme de qualitat quedava reservada als mestres pintors. Un cop més, la diferència qualitativa depenia dels detalls, i així, amb un mateix volum de base, l'aparença i aspecte final podia variar enormement en funció de la destresa del pintor, raó que feia que aquell treball cobrés un especial protagonisme dins el conjunt d'activitats per a la preparació dels entremesos de les respectives en-

\footnotetext{
89 Allò que en castellà s'anomena 'pastillajes'.

90 THOMPSON, Daniel V., 1936, p. 29 i 1956, p. 43.

91 Així doncs, per totes aquestes raons, considerem que el més adient quan parlem de tremps en l'Edat Mitjana i el Renaixement és que ens referim a ells com a tècniques mixtes, ja que comportaven l'ús de diversos aglutinants i no existia un patró massa determinat per a l'elecció del vehicle, i les carències d'uns materials eren esmenades mitjançant la utilització d'altres.
} 
trades reials. Una bona factura pictòrica era indispensable, i aquesta quedava, a més, legitimada per l'(ab)ús de l'or i l'argent. L'oli, però, també va ser-ne protagonista indirecte com a material auxiliar. Amb oli es pintaven les estructures que havien de passar un major temps a la intempèrie, atès que la climatologia i les eventuals pluges no causaven tants danys sobre aquest material com ho haguessin fet sobre els tremps. A banda de serhi a les llotges, cadafals, grades i altres estructures de l'espectacle, molt possiblement se'l considerés com a matèria principal dels vernissos que s'aplicaven, una vegada que l'acabat cromàtic estava enllestit, sobre les roques i carrosses per aillar la pintura de la humitat i per atorgar-ne una textura setinada i lluenta que reforcés l'aparença visual d'aquelles efímers fastuositats.

\subsection{Fulls tenyits, flors de paper}

No podem concloure, però, el tema dels procediments sense fer una menció especial als nombrosos complements que van ser realitzats amb altres tècniques, i entre els que destacaren per la seua abundància les flors de paper. Van comprarse nombroses vegades fulls tenyits de colors, ${ }^{92}$ i en altres ocasions van tenyir-se ${ }^{93}$ papers en blanc que després eren retallats i blegats, en una mena d'exercici de papiroflèxia, formant pètals i fulles que s'hi adherien o lligaven sobre esqueixos de fil d'aram. ${ }^{94}$ La confecció de flors de paper assegurava una nota de bucòlic cromatisme a les desfilades, al temps que es convertia en un recurs per tenir flors -tan mateix fossin fictícies- que perduraven sense fer-se malbé. Cal esmentar també altres elements com màscares i carasses, vestuaris fabricats explícitament, de vegades amb pells d'animals i teles, o altres complements (plomes, banyes, i fins i tot una ossamenta per al personatge de la mort de la Roda de les Edats fabricada amb fustes tallades). En general, tal i com s'ha apuntat a l'apartat dels materials, aquests complements proliferaren, i la consecució de cadascun d'ells responia a un procediment ben divers.

\section{Conclusions}

L'anàlisi de les adquisicions materials confinades a la documentació al·lusiva a ambdues entrades reials ens aporta una sèrie de dades que, més enllà dels seus valors (econòmic, mercantil, social o terminològic, d'entre altres) ens aproximen a un altre tipus de coneixement formal d'aquestes mostres d'art efímer, tot i permetent un estudi dels materials, procediments concrets i les metodologies de treball utilitzades per al disseny, confecció i consecució de les carrosses i escenografies que formaren part d'aquests fasts. Es tracta, al cap i a la fi, d'una lectura que aporta un nou punt de vista a la investigació d'aquelles entrades, una introspecció que ens parla de la seua realitat material i de seua existència pròpia, i que complementa altre tipus d'estudis que $s^{\prime}$ han realitzat al llarg dels darrers anys sobre aspectes ben diversos d'aquestes festes cíviques, que formaren part de la cultura mediterrània i que, al cap i a la fi, no disten gaire d'altres manifestacions artístiques efímeres als territoris de la Corona d'Aragó i que encara perduren als nostres dies.

\section{Bibliografia}

AL-ABBADI, Hossam Mujtar. Las Artes del libro en AlAndalus y el Magreb. Madrid: Ediciones El Viso, 2005.

ALDEA HERNÁNDEZ, Ángela. "La procesión Valenciana del Corpus según las representaciones iconográficas de Fray Bernat Juanera". En: CAMPOS, F. J. (dir). Religiosidad y ceremonias en torno a la eucaristía: actas del simposium. Madrid: Ediciones Escurialenses, 2003, pp. 753-776.

ALEJOS MORÁN, Asunción. "Figuras, símbolos, alegorías y monstruos en el Corpus Valenciano". En: CAMPOS, F. J. (dir). Religiosidad y ceremonias en torno a la eucaristía: actas del simposium. Madrid: Ediciones Escurialenses, 2003, pp. 667-712.

ALIAGA, Joan; TOLOSA, Lluïsa; COMPANY, Ximo (eds.). Documents de la pintura valenciana medieval $i$ moderna II. Llibre de l'entrada del rei Martí I. Valencia: Universitat de València, 2007.

ARMENINI, Gianbattista. De'veri precetti della pittura. Ravenna: Francesco Tebaldini, 1587.

BAZZOCCHI, Flavia. "Un boceto inédito para un retablo de Chiva procedente del Archivo de la Casa Ducal de Medinaceli". En: TERÉS, Maria Rosa (coord.). Capitula facta et firmata: Inquietuds artístiques en el quatrecents. Valls: Cossetània Edicions, 2009, pp. 281-294

BOIX, Vicente. Fiestas Reales. Descripción de la cabalgata y de la procesión del Corpus. Valencia: Imp. De la Regeneración Tipográfica de Don Ignacio Boix, 1858.

CALVO MANUEL, Ana María. "Retablos medievales del norte valenciano". En: VV.AA. Los retablos: Técnicas, materiales y procedimientos, Madrid: 2006: http://ge-iic.com/files/Curso\%20retablos\%202004/anacalvo Retablosnortevalenciano.pdf.

92 Cennini ja esmenta els fulls de color i els procés per tenyir-los (1988, caps. XVI-XXII, pp. 46-52).

${ }_{93}$ Manca encara un treball que abordi en profunditat la relació entre els tintoreres valencians i els pintors. L'ús de laques com la grana i carmini, i d'altres herbes com la reseda, el safrà, l'orxella, l'indi o el pastell està directament vinculat a aquest gremi. Vegeu especialment GARCÍA MARSILLA, Juan Vicente, 2017, pp. 283-316. THOMPSON, Daniel V., 1956 exposa ja perfectament aquesta relació, però molt esclaridor resulta també el llibre de DIODATO, Sergio, 2012.

${ }_{94}$ Aquest element també queda consignat a la documentació, i fins i tot s'especifica, en moltes ocasions, que el seu destí era la confecció de flors de paper. 
CÁRCEL ORTí, María Milagros; GARCÍA MARSILLA, Juan Vicente. Documents de la pintura valenciana medieval i moderna IV: Llibre de l'entrada de Ferran d'Antequera. València: Universitat de València, 2013.

CARRERES ZACARES, Salvador. Ensayo de una bibliografia de libros de fiestas celebradas en Valencia y su antiguo Reino. Vives Mora, 1925.

CENNINI, Cennino. El libro del arte. Madrid: Ediciones AKAL, 1988.

CHAMORRO, Alfredo. "Les relacions entre Barcelona i la monarquia mitjançant les entrades reials". Pedralbes: revista d'història moderna, 2009, $\mathrm{n}^{\circ} 29$, pp. 427-437.

CLARKE, Mark. The Art of All Colours: Mediaeval Recipe Books for Painters and Illuminators. London: Archetype, 2001.

CLARKE, Mark. Mediaeval Painters' Materials and Techniques: The Montpellier Liber Diversarum Arcium. London: Archetype, 2011.

COMPANY, Ximo. Paolo de San Leocadio i els inicis del Renaixement a València. Gandia: CEIC Alfons el Vell, 2006.

COMPANY, Ximo. "De España a Italia. Artistas hispanos en la 'koiné' mediterránea de los siglos XV y XVI". En: COMPANY, X.; VILALTA M. J.; PUIG, I. (eds.). El rol de lo hispano en la pintura mediterrània de los siglos XV y XVI. Lleida: Garsineu Edicions, 2009, pp. 15-50.

COLOMINA, Antoni. "La tradición del cartón-piedra en la imaginería festiva valenciana". En: ROMÁN, R. M.; CATALÁN, José Ignacio (coords). Escultura Ligera. Valencia: Ayuntamiento de Valencia, 2017, pp. 109-119.

CÓRDOBA DE LA LLAVE, Ricardo. "Un recetario técnico castellano del siglo XV: el manuscrito H490 de la Facultad de Medicina de Montpellier". En la España medieval, 2005, vol. 28, pp. 7-48.

CÓRDOBA DE LA LLAVE, Ricardo. Ars mechanicae: ingeniería medieval en España. Madrid: Gobierno de España, Ministerio de Fomento, 2008.

CRIADO VEGA, Teresa. Tratados y recetarios de técnica industrial en la España medieval. La Corona de CastiIla, siglos XV-XVI. Tesis Doctoral. Universidad de Córdoba, 2013.

DIODATO, Sergio. I buoni colori di una volta. Firenze: Menabò, 2012 (2010).

DOERNER, Max. Los materiales de pintura y su empleo en el arte. Barcelona: Reverté, 1998.

FERRER VALLS, Teresa. "La fiesta cívica en la ciudad de Valencia en el siglo XV". En: Cultura y representación en la edad media: actas del seminario celebrado con motivo del II Festival de Teatre i Música Medieval d'Elx, octubre-noviembre de 1992. Alacant: Instituto Alicantino Juan Gil-Albert, 1994, pp. 145-169.

FERRERO, José Luis et al. "Análisis mediante EDXRF de obras de la pintura Gótica y Renacentista Valenciana". En: Recuperando Nuestro Patrimonio II. Valencia, Generalitat Valenciana, 2002, pp. 286-293.

GARCÍA MARSILLA, Juan Vicente. La jerarquía de la mesa: los sistemas alimentarios en la Valencia bajomedieval. Valencia: Centre d'Estudis d'Història Local, 1993.

GARCÍA MARSILLA, Juan Vicente. "El poder visible: demanda y funciones del arte en la corte de Alfonso el Magnánimo". Ars Longa: cuadernos de arte, 1996, n 7, pp. 33-47

GARCÍA MARSILLA, Juan Vicente. "El precio de la belleza. Mercado y cotización de los retablos pictóricos en la Corona de Aragón (siglos XIV y XV)". En: DENJEAN, C. Sources sérielles et prix au Moyen âge: travaux offerts à Maurice Berthe. Toulouse: CNRS-Université de Toulouse-Le Mirail, 2009, pp. 253-290.
GARCÍA MARSILLA, Juan Vicente. La taula del senyor duc. Alimentació, gastronomia i etiqueta a la cort dels ducs reials de Gandia. Gandia: CEIC Alfons el Vell, 2010

GARCÍA MARSILLA, Juan Vicente. "Los colores del textil. Los tintes y el teñido de los paños en la valencia medieval". Guido Castelnuovo, y Sandrine Victor (eds.) L'Histoire à la source : acter, compter, enregistrer (Catalogne, Savoie, Italie, XII e -XV e siècle) Mélanges of ferts à Christian Guilleré, Volume 1, 2017, pp. 283-316.

GARCÍA, Greta; ROMÁN, Rosa María. "La imagen original de la Virgen de los Desamparados de la Real Basílica de Nuestra Señora de los Desamparados de Valencia. Una escultura de papelón. Investigación y restauración". En: ROMÁN, R. M.; CATALÁN, J. I. (coord.) Escultura Ligera. Valencia: Ayuntamiento de Valencia, 2017, pp. 147-160.

GÓMEZ-FERRER, Mercedes. "Aportaciones sobre el pintor valenciano Bartomeu Baró (Doc. 1451-1481)". Ars Longa: cuadernos de Arte, 2009, n 18, pp. 81-89.

GONZÁLEZ-MARTÍNEZ, Enriqueta. Tratado del Dorado, plateado y su policromia. Tecnología, Conservación y Restauración. Valencia: Universitat Politècnica de València, 2014 (1997).

HILL Donald. R. "Ingeniería mecánica del Islam medieval". En: GARCíA, N. (ed.). Historia de la técnica. Barcelona: Prensa Científica, 1994, pp. 22-28.

HUERTAS, Manuel. Materiales, procedimientos y técnicas pictóricas I: Soportes, materiales y útiles empleados en la pintura de caballete. Barcelona: Ediciones AKAL, 2010(a).

HUERTAS, Manuel. Materiales, procedimientos y técnicas pictóricas II. Barcelona: Ediciones AKAL, 2010(b).

IBÁÑEZ, Javier. "Entre 'muestras' y 'trazas'. Instrumento, funciones y evolución de la representación gráfica en el medio artístico hispano entre los siglos XV y XVI. Una aproximación desde la realidad aragonesa". En: ALONSO, B. (coord.). Arquitectura tardogótica en la Corona de Castilla: trayectorias e intercambios, SeviIla-Santander. Santander: Universidad de Cantabria / Universidad de Sevilla, 2014, pp. 305-328.

IZQUIERDO, Teresa. "La corporación de carpinteros de Valencia: consolidación y construcción de su identidad corporativa", En: Incipit 2. Workshop de Estudos Medievais da Universidade do Porto, Poto: Universidade do Porto, 2012, pp. 105-116.

KIRBY, Jo; NASH, Susie; CANNON, Joanna (eds.). Trade in Artists' Materials: Markets and Commerce in Europe to 1700. London: Archetype, 2010.

KIRBY, Jo; VAN BOMMEL, Maarten; VERHECKEN, André. Natural colorants for dying and lake pigments: practical recipes and their historical sources. Archetype, 2014.

KOVÁCS, Lenke. "La ciutat com a escenari: les entrades reials i la festa urbana". Barcelona quaderns d'història, 2003, n. 9, pp. 71-82.

KROUSTALLIS, Stefanos. "Binding media in medieval manuscript illumination: a source research colour in medieval written sources". Revista de História da Arte: medieval colours. Between beauty and meaning, vol. 1, 2011(a), pp. 112-125.

KROUSTALLIS, Stefanos. "Quomodo decoretur pictura librorum: materiales y técnicas de la iluminación medieval". Anuario de estudios medievales, $\mathrm{n}^{\circ} 41$, 2011(b), pp. 775-802.

LADERO, Miguel Angel. "La fiesta en la Europa mediterránea medieval". Cuadernos del CEMYR, 1994, n² 2, pp. 11-52. 
LOBATO, María Luisa. "Cronología de loas, entremeses y bailes de Agustín Moreto". Criticón, 1989, vol. 46, pp. 125-134.

LÓPEZ CONDE, Rubén. "A propósito del Crucificado de Bernini en El Escorial: el Crucifijo de Cartapesta del cardenal Sforza Pallavicino". Archivo Español de Arte, 2011, vol. 84, n 335, pp. 211-226.

MASSIP, Francesc: "Imagen y espectáculo del poder real en la entronización de los Trastámara (1414)". En VV.AA. El poder real en la Corona de Aragón (siglos XIV-XVI). Actas del XV Congreso de Historia de la Corona de Aragón. Zaragoza: Gobierno de Aragón, T. I. vol. 3, 1996, pp. 371-386.

MASSIP, Francesc: La monarquía en escena. Teatro, fiesta y espectáculo del poder en los reinos ibéricos: de Jaume el Conquistador al príncipe Carlos de Gante. Madrid: Consejería de las Artes, col. Música y Teatro Medieval, núm. 7, 2003.

MASSIP, Francesc. "L'entrada valenciana dels primers Trastàmares". Locus amoenus, 2013-2014, n. 12, pp. 55-65.

MATTEINI, Mauro; MOLES, Arcangelo. La química en la restauración: los materiales del arte pictórico. Editorial Nerea, 2001.

MAYER, Ralph. Materiales y técnicas del arte. Madrid: Ediciones AKAL, 1993.

MERRIFIELD, Mary P. Medieval and Renaissance treatises on the arts of painting: original texts with English translations. London: Dover Publications, 1967.

MIRÓ BALDRICH, Ramon. "Els entremesos del Corpus a Cervera". Miscel/lània Cerveria, 1985, núm. 3, pp. 73-96.

MIQUEL, Matilde. Retablos, prestigio y dinero: Talleres y mercado de pintura en la Valencia del gótico internacional. Valencia: Publicacions de la Universitat de València, 2008.

MOLINA, Joan. "La participació dels pintors en les cerimònies i espectacles quatrecentistes de Barcelona i Girona". En: Formes teatrals de la tradició medieval, Actes del VII Col.loqui de la Société Internationale Pour l'Étude du Téâtre Médiéval. Barcelona: Institut del Teatre, 1992, pp. 173-180.

MONTERO, Encarna. "El sentido y el uso de la 'Mostra' en los oficios artísticos. Valencia, 1390-1450". Boletín del Museo e Instituto Camón Aznar, 2004, n 94, pp. 221-254.

MONTERO, Encarna. La transmisión del conocimiento en los oficios artísticos, Valencia, 1370, 1450 (Tesis Doctoral). València: Universitat de València, 2013(a).

MONTERO, Encarna. "El cuaderno de dibujos de los Uffizi: Un ejemplo, tal vez, de la transmisión del conocimiento artístico en Valencia en torno a 1400". Ars Longa, 2013(b), $n^{\circ} 22$, pp. 55-76.

MONTERO, Encarna. La transmisión del conocimiento en los oficios artísticos, Valencia, 1370, 1450. València: Institució Alfons el Magnànim, Diputació de València, 2015.

MONTERO, Encarna. "Noticias sobre la escultura en papel en Valencia y la Corona de Aragón durante la Baja Edad Media". En: ROMÁ, Rosa Mª ; CATALÁN, José Ignacio (coords.). Escultura Ligera. Valencia: Ayuntamiento de Valencia, 2017, pp. 99-108.

NARBONA, Rafael. "Las fiestas reales en Valencia entre la Edad Media y la Edad Moderna (siglos XIVXVII)". Pedralbes: revista d'història moderna, 1993, $n^{\circ} 13$, pp. 463-472.

NARBONA, Rafael. "Apreciaciones históricas e historiográficas en torno a la fiesta del Corpus Christi de Valencia". Revista d'història medieval, 1999, n 10, pp. 371-382.
NARBONA, Rafael. Memorias de la ciudad. Ceremonias, creencias y costumbres en la historia de Valencia. Valencia, Ajuntament de València, 2003.

RAUFAST, Miguel. "'E vingueren los officis e confraries ab llurs entremeses e balls'. Una aproximación al estamento artesanal en la Barcelona bajomedieval, a partir del estudio de las ceremonias de entrada real". Anuario de Estudios Medievales, 2006, vol. 36, n. 2, pp. 651-686.

RAUFAST, Miguel. " ¿Un mismo ceremonial para dos dinastías? Las entradas reales de Martín el Humano (1397) y Fernando I (1412) en Barcelona". En la España medieval, 2007, vol. 30, pp. 91-130.

RINALDI, Simona, et al. La fabbrica dei colori. Pigmenti e coloranti nella pittura e nella tintoria. Roma: II Bagatto, 1986.

ROSSI-RÒISS, Enzo. Cartapesta e cartapestai. Macerata: Libera Università Europea, 1983.

SANCHIS SIVERA, José. Pintores Medievales en Valencia. Valencia: L'Avenç, 1914.

SARRIÓ, Ma Francisca; JUANES, David; FERAZZA, Livio. "La imagen de San Miguel Arcángel del Ayuntamiento de Valencia. Análisis del sistema constructivo mediante el estudio con tomografía computarizada (TC)". En: ROMÁ, R. M.; CATALÁN, J.I. (coords.). Escultura Ligera. Valencia: Ayuntamiento de Valencia, 2017, pp. 9-24.

SIERRA, Carlos. "Mecánica andalusí: otra faz de nuestra historia secreta". Revista Universidad de Antioquía, 2011, n 306, pp. 40-49.

SIMÓN, José Manuel; VIVANCOS, María Victoria; GRAFIÁ, José Vicente. "Estudio de las alteraciones y posterior intervención de restauración del carro triunfal 'Roca Diablera'". Arché, 2010, n 4-5, pp. 69-72.

TALAMANTES PIQUER, María del Carmen. La Roca Valencia: estudio preliminar de la policromía y su limpieza. (Trabajo de fin de máster). Universitat Politècnica de València, 2012.

THOMPSON, Daniel V. The materials and tecniques of medieval painting (Dover Art Instruction). Dover Publications, 1956.

THOMPSON, Daniel V. The practise of tempera painting. Yale: University Press, 1936.

VENTURA, Agustí. "Orígens del paper a Xàtiva". En: La impremta valenciana: [Exposició]. València: Conselleria de Cultura, Educació i Esport, 1990, pp. 123-142.

TOSATTI, Silvia Bianca. II manoscritto veneziano: un manuale di pittura e altre arti-miniatura, incisione, vetri, vetrate e ceramiche-di medicina, farmacopea e alchimia del Quattrocento. Milano: CARMAS, 1991.

TOSATTI, Silvia Bianca. Trattati medievali di tecniche artistiche. Milano: Jaca Book, 2007.

VERNET, Juan. "Ingeniería mecánica del Islam Occidental". Investigación y Ciencia, 1993, n. ${ }^{\circ} 201$, pp. 46-50.

VIDAL FRANQUET, Jacobo. El pintor de la ciutat, Tortosa, segles XIV-XV. Tortosa: Cossetània, 2011, pp. 12-22.

ZARAGOZÁ, Arturo. "Los moldes de máscaras para disfraces procedentes del Palacio del Marqués de Villores de San Mateo (Castellón)". En: ROMÁN, Rosa Ma ; CATALÁN, José Ignacio (coords.). Escultura Ligera. Valencia: Ayuntamiento de Valencia, 2017, pp. 79-84.

ZOZAYA, Juan. "Construcción naval e ingeniería portuaria en el mundo antiguo y medieval". En: Puertos españoles en la historia. Madrid: Centro de estudios históricos de obras públicas y urbanismo, 1994, pp. 43-60. 